Check for updates

Cite this: RSC Adv., 2020, 10, 9210

\title{
Synergetic treatment of dye contaminated wastewater using microparticles functionalized with carbon nanotubes/titanium dioxide nanocomposites $\dagger$
}

\author{
Zheng Lian, ${ }^{\text {abc }}$ Chaohui Wei, ${ }^{d}$ Bin Gao, ${ }^{e}$ Xiaogang Yang, ${ }^{b}$ Yue Chan, ${ }^{f}$ Jing Wang, ${ }^{\mathrm{g}}$ \\ George Zheng Chen, (D) ${ }^{\text {dh }}$ Kai Seng Koh, ${ }^{i}$ Yong Shi, ${ }^{\text {bc }}$ Yuying Yan, ${ }^{c j}$ Yong Ren, (D) *bc \\ Jun $\mathrm{He}$ (D) ${ }^{* d}$ and $\mathrm{Fu}$ Liu (D)*k
}

\begin{abstract}
The highly efficient treatment of azo dye contaminated wastewater from the textile industry is an important but challenging problem. Herein, polydimethylsiloxane (PDMS) microparticles, incorporating multiple-walled carbon nanotubes/titanium dioxide ( $\mathrm{MWCNTs} / \mathrm{TiO}_{2}$ ) nanocomposites, were successfully synthesized to treat wastewater containing Rhodamine B (RhB) dyes in a synergetic approach, by combining sorption and photocatalytic degradation. The surfactant wrapping sol-gel method was applied to synthesize MWCNTs/TiO nanocomposites with $\mathrm{TiO}_{2}$ nanoparticles evenly distributed on the surface of the MWCNTs. The PDMS microparticles were fabricated with an oil-in-water $(\mathrm{O} / \mathrm{W})$ single emulsion template, using needle-based microfluidic devices. MWCNTs/TiO 2 nanocomposites (at a weight ratio of $1 \%$, and $2 \%$, respectively) were mixed with the PDMS precursor as the dispersed phase, and an aqueous solution of polyvinyl alcohol (PVA) was used as the continuous phase. Highly monodispersed microparticles, with average diameters of $692.7 \mu \mathrm{m}$ (Coefficient of Variation, $\mathrm{CV}=0.74 \%$ ) and $678.3 \mu \mathrm{m}(\mathrm{CV}=1.04 \%$ ), were formed at an applied flow rate of the dispersed and continuous phase of 30 and $200 \mu \mathrm{L} \mathrm{min}{ }^{-1}$, respectively. The fabricated hybrid microparticles were employed for the treatment of RhB, involving a dark equilibrium for 5 hours and UV irradiation for 3 hours. The experimental conditions of applied PDMS type, mass loading amount, treatment duration, photodegradation kinetics, initial concentration of pollutants and environmental $\mathrm{pH}$ values were investigated in this work. The PDMS microparticles with $2 \mathrm{wt} \% \mathrm{MWCNTs} / \mathrm{TiO}_{2}$ nanocomposites can exhibit a removal efficiency of $85 \%$. Remarkably, an efficiency of $70 \%$ can be retained after the microparticles have been recycled and reused for 3 cycles. The PDMS-MWCNTs/TiO 2 microparticles possess a superior performance over conventional treatment approaches for dye contaminated wastewater, especially in recyclability and the prevention of secondary pollution. This work provides a feasible and eco-friendly route for developing an efficient and low-cost microfluidic method for treating complicated water environmental systems.
\end{abstract}

Received 25th December 2019

Accepted 23rd February 2020

DOI: 10.1039/c9ra10899h

rsc.li/rsc-advances

\section{Introduction}

Synthetic dyes contained in textile wastewater, such as azo dyes, pose a great threat to the global aqueous environments and even damage the aquatic life. ${ }^{1}$ Azo dyes are generally considered hard to degrade, because of the stable aromatic structures with nitrogen-nitrogen double bonds. ${ }^{2}$ Many efforts have been made to exploit feasible solutions to mitigate their negative impacts, anternational Doctoral Innovation Centre, University of Nottingham Ningbo China, Ningbo, China

${ }^{b}$ Department of Mechanical, Materials and Manufacturing Engineering, University of Nottingham Ningbo China, Ningbo, China.E-mail:yong.ren@nottingham.edu.cn ${ }^{c}$ Research Group for Fluids and Thermal Engineering, University of Nottingham Ningbo China, Ningbo, China

${ }^{d}$ Department of Chemical and Environmental Engineering, University of Nottingham Ningbo China, Ningbo, China. E-mail: jun.he@nottingham.edu.cn

${ }^{e}$ ECO Environmental Investment Limited, Hong Kong, China

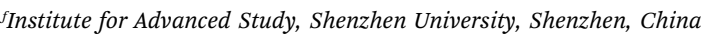

${ }^{g}$ Department of Electrical and Electronic Engineering, University of Nottingham

Ningbo China, Ningbo, China
${ }^{h}$ Department of Chemical and Environmental Engineering, University of Nottingham, Nottingham, UK

${ }^{i}$ School of Engineering and Physical Sciences, Heriot-Watt University Malaysia, Putrajaya, Malaysia

${ }^{j}$ Research Group for Fluids and Thermal Engineering, University of Nottingham, Nottingham, UK

${ }^{k}$ Ningbo Institute of Materials Technology and Engineering, Chinese Academy of Sciences, Ningbo, China.E-mail: fu.liu@nimte.ac.cn

$\dagger$ Electronic supplementary information (ESI) available. See DOI: 10.1039/c9ra10899h 
such as physisorption, chemical treatment, advanced oxidation processes, biological decomposition, photodegradation, and electrocoagulation. ${ }^{3-7}$ Among these treatment techniques, it is preferable to promote efficient and eco-friendly methodologies that contribute minimal secondary pollutants from the treatment processes or chemical residues. Recently, polydimethylsiloxane (PDMS) has been an attractive material applied for organic compounds removal from water. ${ }^{8-11}$ It is an elastomeric polymer, consisting of repeated units of $\mathrm{OSi}\left(\mathrm{CH}_{3}\right)_{2} \mathrm{O}$, which are advantageous for the uptake of hydrophobic organics in water/oil separation ${ }^{12-17}$ as well as the selective sorption of small molecules dissolved in solutions. ${ }^{18,19}$ Dye molecules attach onto the surface of PDMS through interactions with nonpolar hydrophobic chains, such as methyl branches, and then gradually migrate into the elastomer matrix. ${ }^{20}$ Hence, PDMS can also be a good candidate for microextraction applications or the removal of dye pollutants in bodies of water. However, the effect of removal by PDMS is mainly attributed to physical sorption of target pollutants. Therefore, further treatment is normally needed as the contaminants are only transferred from one media to another via a reversible physisorption mechanism, allowing for subsequent desorption back into the environment.

Heterogeneous photocatalysis provides an alternative solution to eliminate organic compounds in a more complete and green manner. Anatase $\mathrm{TiO}_{2}$, among the three common titanium polymorphs (anatase, rutile, brookite), has the highest photodegradation ability, showing to degrade a range of organic species to $\mathrm{CO}_{2}, \mathrm{H}_{2} \mathrm{O}$ as well as other mineral acids under irradiation. ${ }^{21,22}$ Thus, it has been widely utilized in environmental pollution mitigation methods such as water purification and air pollution treatment. ${ }^{23,24}$ The photocatalytic reactions should be performed under visible or UV light due to the large band gap of anatase $\mathrm{TiO}_{2}\left(E_{\mathrm{bg}}=3.2 \mathrm{eV}\right)$. Electrons in the valence band of a semiconductor $\left(\right.$ i.e. $\left.\mathrm{TiO}_{2}\right)$ are excited to the conduction band, leaving a hole with positive charge. The generated hole subsequently leads to the formation of free radicals that exhibit strong oxidizing properties to break chemical bonds of organic molecules, an example of this, using $\mathrm{TiO}_{2}$ in an aqueous solution, is described below: ${ }^{25,26}$

$$
\begin{gathered}
\mathrm{TiO}_{2}+h \nu \text { (irradiation) } \rightarrow \mathrm{TiO}_{2}\left(\mathrm{e}^{-}+\mathrm{h}^{+}\right) \\
\mathrm{h}^{+}+\mathrm{H}_{2} \mathrm{O} \rightarrow \mathrm{H}^{+}+\cdot \mathrm{OH} \\
\mathrm{e}^{-}+\mathrm{O}_{2} \rightarrow \cdot \mathrm{O}_{2}^{-} \\
\text {Pollutants }+\cdot \mathrm{OH} \rightarrow \text { degradation products } \\
\text { Pollutants }+\cdot \mathrm{O}_{2}^{-} \rightarrow \text { degradation products }
\end{gathered}
$$

However, the recombination of photon generated electronhole pairs may occur in a scale of nanoseconds and which significantly limits the photodegradation efficiency. ${ }^{27}$ In recent decades, CNTs have been widely used as substrates and electron acceptors for $\mathrm{TiO}_{2}$ due to the higher work function $(4.95 \mathrm{eV})$ than $\mathrm{TiO}_{2}$ leading to electron diffusion from $\mathrm{TiO}_{2}$ to CNTs, preventing the recombination of the electron-hole pair. ${ }^{28}$ Moreover, photocatalytic efficiency of the composite could be enhanced, owing to the high charge carrier mobility, the overall adsorption capacity, electron scavenging ability. ${ }^{29,30}$ Many approaches have been developed to deposit $\mathrm{TiO}_{2}$ onto the surface of CNTs. For instance, Gao et al. ${ }^{31}$ promoted surfactant-wrapping sol-gel methods to synthesize $\mathrm{CNTs} / \mathrm{TiO}_{2}$ nanocomposites with even distribution of $\mathrm{TiO}_{2}$ nanoparticles on the surface of the MWCNTs and displayed high photocatalytic efficiency on Methyl Blue under UV-A irradiation. Zhu et $a .^{32}$ fabricated rice grain-shaped MWCNTs/ $/ \mathrm{TiO}_{2}$ nanocomposites via the electrospinning method in order to successfully decompose a Alizarin Red dye. Liu et al. ${ }^{33}$ synthesized double-walled carbon nanotubes- $\mathrm{TiO}_{2}$ hybrid by a/the hydrothermal method to efficiently deal with sulfathiazole under visible light irradiation. Hamid and coworkers ${ }^{34}$ also developed $\mathrm{CNTs} / \mathrm{TiO}_{2}$ composites through a modified sol-gel method to degrade Black 5 dye. Li et al. ${ }^{35}$ fabricated $\mathrm{SWCNT} / \mathrm{TiO}_{2}$ nanocomposites (single-walled carbon nanotubes) using a/the lowtemperature hydration and evaporation-drying process for bacteriophage MS2 inactivation and nitrobenzene degradation under UV-A irradiation. Though, the enhancements of these reported methods have significantly enhanced the overall photocatalytic reaction efficiency, all reported composites that are compared used $\mathrm{TiO}_{2}$ alone. Furthermore, recycling of nanocomposites after the treatment and secondary water pollution due to nanocomposite residues are some of the remaining challenges faced.

A potential solution for these remaining challenges is the immobilization of nanoparticles onto substrates. Typically, the substrates are much larger than the nanocomposites, allowing for recycling and recovery by simple filtration. In addition, the substrate could act as sorbents to enhance the treatment process, creating synergetic effects that combine sorption and photodegradation of pollutants in the composite materials or performing self-clean surfaces. ${ }^{36}$ Hickman et al. ${ }^{37}$ provided evidence for this concept by fabricating a porous $\mathrm{PDMS} / \mathrm{TiO}_{2}$ sponge to sorb and photodegrade organic compounds; while Lee et $a .^{38}$ developed this further by demonstrating recyclable $\mathrm{TiO}_{2}$ hybrid sponges with PDMS to treat variety of pollutants by sorption and photo-degradation. It was shown that the integration of $\mathrm{TiO}_{2}$ nanoparticles into PDMS can not only contribute to the photodegradation efficiency but also modify physical and chemical properties of the PDMS substrate, increasing the strength and strain at break, ${ }^{39}$ improving corrosion and temperature resistance as well as water impact. ${ }^{40}$ However, the previous work discussed above was based on dispersion or embedding $\mathrm{TiO}_{2}$ nanoparticles into bulk materials and may lead to low efficiency or even waste of substrate materials. In recent years, increased attention has been given to droplet microfluidics, with the promotion of widespread adoption of this technique to many industries such as chemistry, food, cosmetics, and pharmaceutical industries. ${ }^{41,42}$ Microfluidics could manipulate droplets into tailored sizes, shapes, structures and components in microscale resolution. A microfluidic platform consumes a relatively small amount of raw materials to realize high synthesis efficiency of droplets. These controllable droplets are formed using different templates such as single emulsion, double emulsion, Janus, multiple cored, higher order of emulsion templates, and so on. ${ }^{43-46}$ Produced droplets can then be solidified, under thermal 
or irradiative conditions, to form microparticles. It is important to highlight that the solidified microparticles exhibit varying functions, depending on the dopants added. For example, Han et $a .^{47}$ adopted microfluidics to combine chitosan with $\mathrm{TiO}_{2}$ to generate chitosan/ $\mathrm{TiO}_{2}$ microparticles for treatment of methylorange dye.

To the best of our knowledge, there has been no work reported about the generation of microparticles using microfluidic techniques that combine MWCNTs/TiO ${ }_{2}$ and PDMS for the purpose of wastewater treatment. In this research, we employed the surfactant wrapping sol-gel method to fabricate MWCNTs/TiO nanocomposites, with a uniform distribution of $\mathrm{TiO}_{2}$ deposited on the surface of MWCNTs. The MWCNTs/TiO 2 nanocomposite was further integrated with PDMS, to make PDMS-MWCNTs/ $\mathrm{TiO}_{2}$ microdroplets, by microfluidics via needle-based microfluidic devices in parallel connection modes. The droplets were thermally cured to form microparticles which were subsequently used for the treatment of simulated wastewater containing a model dye, Rhodamine B (RhB). In this work, the sorption process and photodegradation ability of PDMS-MWCNTs/TiO microparticles under UV irradiation conditions were examined. Recycling and reuse experiments of the microparticles were also performed. This study enables a facile way to form functional materials with micro/nano hybrid structure, leading to a deeper understanding of the synergetic effect between physical sorption and photocatalysis, and will promote new insights for applying microfluidics in water treatment.

\section{Materials and methods}

\subsection{Acid treatment of MWCNTs}

$1 \mathrm{~g}$ of MWCNTs (purchased from Aladdin, China) was mixed with $60 \mathrm{~mL}$ concentrated sulphuric acid (99\%, Sigma-Aldrich, Shanghai, China) for one hour of ultrasonication until a uniform dispersion was formed. Then, $40 \mathrm{~mL}$ concentrated nitrogen acid (Sigma-Aldrich, Shanghai, China) was slowly added into the mixture and refluxed at 115 to $120^{\circ} \mathrm{C}$ for $15 \mathrm{~min}$ under vigorous stirring. The mixture was cooled to room temperature after the reaction, filtrated and washed with deionized (DI) water until the $\mathrm{pH}$ of the filtrate was neutral. The remaining black residue was dried in an oven at $60{ }^{\circ} \mathrm{C}$ for ten hours and milled into a powder for use.

\subsection{MWCNTs/ $/ \mathrm{TiO}_{2}$ nanocomposite fabrication by surfactant wrapping sol-gel methods}

In order to obtain evenly distribution of $\mathrm{TiO}_{2}$ along the MWCNTs, the surfactant wrapping sol-gel method was implemented as developed by Gao et al. ${ }^{31}$ Sodium dodecylbenzenesulfonate (NaDDBS), titanium isopropoxide (TTIP), ethanol, glacial acetic acid and ammonia solution were obtained from Sigma-Aldrich, China. $35 \mathrm{mg}$ acid treated MWCNTs was mixed with NaDDBS solution under ultrasonication for 2 hours. After sonication, the MWCNTs suspension was transferred into a $20 \mathrm{~mL}$ ethanol beaker under slow stirring for $30 \mathrm{~min}$. This solution was labeled as Solution I. The predetermined amount of TTIP was mixed with $15 \mathrm{~mL}$ ethanol and $3 \mathrm{~mL}$ glacial acetic acid and stirred for $30 \mathrm{~min}$. This solution was labeled as Solution II. Solution II was added dropwise into Solution I, using a syringe pump (Longer, LSP02-1B, China) at a pre-set speed, under vigorous stirring; forming Solution III, which was continually stirred for another two hours. Ammonia solution was then added dropwise into Solution III until pH reached 7. Another $10 \mathrm{~mL}$ ethanol was then added, and the mixture was allowed stirred for an additional $30 \mathrm{~min}$. The suspension was subsequently centrifuged, and the precipitate was washed with ethanol and dried in oven at $120{ }^{\circ} \mathrm{C}$ for an hour. The dried products were calcined at $500{ }^{\circ} \mathrm{C}$ (KSL-1200X, China) for $30 \mathrm{~min}$ after which the final products were carefully milled and collected for use.

\subsection{Characterization of MWCNTs/TiO $/ \mathrm{Tin}_{2}$ nanocomposites}

The fabricated MWCNTs/TiO 2 nanocomposites were characterized by X-ray diffractions (XRD, Bruker D8 Advance, Germany) to confirm the degree of crystallinity, under an operation condition of $2 \theta$ from $10^{\circ}$ to $80^{\circ}$ with $0.02^{\circ} \mathrm{s}^{-1}$ scanning speed. Thermogravimetric analyses (TGA, EXSTAR6000 TG/DTA6300, Japan) was utilized to quantitatively analyze the carbon content in the composites. The samples were heated to $1000{ }^{\circ} \mathrm{C}$ with a heating rate of $20{ }^{\circ} \mathrm{C} \mathrm{min}^{-1}$ in air. Scanning Electron Microscope (SEM, ZEISS Sigma 500), Energy Dispersive X-ray Detector (EDX, OXFORD INCA, assembled with SEM), Transmission Electron Microscope (TEM, JEOL JEM-2100F, Japan) were applied to record and analyze the morphologies and elemental compositions of the nanocomposites.

\subsection{Fabrication of PDMS-MWCNTs/TiO ${ }_{2}$ microparticles by microfluidics}

For microfluidic experiments, polyvinyl alcohol (PVA, SigmaAldrich, Shanghai, China) was dissolved in DI water at a weight ratio of $5 \%$ as the continuous phase. PDMS (Sylgard 184 silicone elastomer) was purchased from Dow Corning (USA) and applied as the dispersed phase which was a mixture of $10: 1$ weight ratio for monomer and curing agent. MWCNTs/ $\mathrm{TiO}_{2}$ nanocomposites were added into the monomer in a predetermined mass. The mixture was then stirred manually for $5 \mathrm{~min}$ and degassed under vacuum for $20 \mathrm{~min}$. The microfluidic devices were assembled from two dispensing needles, polypropylene (PP) cross links, glass capillaries and silicon soft tubes. This needle-based microfluidic device was based on work by Li et al. ${ }^{48}$ with the slight modification to make it glue-free, so that the connection of each part was made by soft tubes. The needles utilized were defined as the inlet needle (21G, I.D. $=510$ $\mu \mathrm{m}$, O.D. $=800 \mu \mathrm{m})$ and outlet needle $(20 \mathrm{G}$, needle holder removed, I.D. $=600 \mu \mathrm{m}$, O.D. $=900 \mu \mathrm{m})$ that were connected by the cross link. The outlet needle (needle holder removed) was linked to a thin glass capillary for better observation of the formed droplets. Syringes were connected through the soft tubes to introduce fluids into the microfluidic device. The PDMS precursor was pumped into the $21 \mathrm{G}-20 \mathrm{G}$ needle-based microfluidic device through the inlet needle under a flow rate of $30 \mu \mathrm{L} \mathrm{min}{ }^{-1}$. The continuous phase was introduced through the upper and lower entrance of the cross link at a flow rate of 


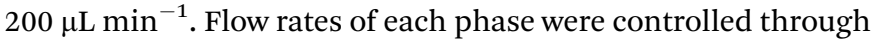
syringe pumps (Longer, LSP02-1B, China). The PDMS precursor was sheared into droplets under the competition of shear force and surface tension between the two phases that the process is schematically illustrated in Fig. 1A. A 3D demonstration of the PDMS-MWCNTs/ $/ \mathrm{TiO}_{2}$ microdroplet generation process can be found in Fig. S1 in the ESI. $\dagger$ Subsequently, the PDMS microdroplets were directed through the outlet needle that linked with a glass capillary for observation and collection. The mixture is defined as PDMS-MWCNTs/TiO ${ }_{2}$. For reference, other types of PDMS are referred to as PDMS-P (pristine PDMS), PDMS-M (PDMS + MWCNTs), PDMS-T (PDMS + $\mathrm{TiO}_{2}$, anatase titanium dioxide purchased from Aladdin, China) that were fabricated in the same manner. In the previous studies, it was found that for a type of microparticles, the amount of pollutant removed was mainly dependent on the mass of particles released instead of particle sizes, ${ }^{\mathbf{9}, 49}$ hence in this research the investigation was focused on the effect of mass loading. In line with this, the flow rates of each phase and modes of needles, which could determine the sizes of microparticles were thus fixed in this study.

The fabricated PDMS microdroplets were collected in a beaker and thermally cured to solid particles at $70{ }^{\circ} \mathrm{C}$ for 2 hours off-site. PDMS microdroplets and microparticles were observed under an optical microscope (N-800F, Ningbo Novel Optics, China). A computer connected to this microscope captured images and measure the target sizes using the software ImageJ. At least 200 samples were captured and analyzed with ImageJ. Average diameters (AD) and standard deviations (STDV) were applied to calculate the value of CV as follows:

$$
\mathrm{CV}=\frac{\mathrm{STDV}}{\mathrm{AD}} \times 100 \%
$$

We have developed a small microfluidic component known as two-way connector (TWC) to connect microfluidic devices in parallel, to enhance the production yields and therefore save the use of additional pumps. In Fig. 1B, four 21G-20G needle based microfluidic devices connected by several TWCs to obtain roughly fourfold yield compared with a single device. The solidified PDMS-MWCNTs/TiO ${ }_{2}$ microparticles were washed three times with DI water and stored at ambient conditions.

\subsection{Sorption and photodegradation experiments of Rhodamine B wastewater}

The PDMS microparticles were released into small tubes that contained RhB dye (Sigma-Aldrich, China) simulated wastewater. The tubes were fixed in an OCRS-K mode photocatalytic reactor (365 $\mathrm{nm}$ fillers were equipped, Henan, China) that was able to support the light source lamp in the center so that each tube could receive irradiation equally. The reactor was equipped with a motor in the bottom plate to provide stirring functions. Working temperature of lamp was maintained by a cooling water circulation unit at $10^{\circ} \mathrm{C}$ and the reaction temperature was at room temperature. The reactor was installed in a dark case to ensure dark environment and avoid influence from exterior lights. In the sorption experiment, the samples were placed in dark environment with stirring functions turned on while in photodegradation experiment, stirring, lamp and cooling unit were turned on. Concentration measurement of sample water was conducted on a Thermo Scientific Evolution 201 UV-Visible Spectrometer (USA) with a scanning range from $700 \mathrm{~nm}$ to $300 \mathrm{~nm}$ and a scanning speed of $1 \mathrm{~nm} \mathrm{~s}^{-1}$. Quantitative measurements were set at the maximum absorption peak of RhB (554 nm). The conversion of absorbance intensity to concentration values were conduction by the preparation of calibration curves of RhB solutions from $1 \mathrm{mg} \mathrm{L}^{-1}$ to $20 \mathrm{mg} \mathrm{L}^{-1}$. The removal efficiency was calculated by:

$$
\eta=\frac{C_{0}-C_{t}}{C_{0}} \times 100 \%
$$

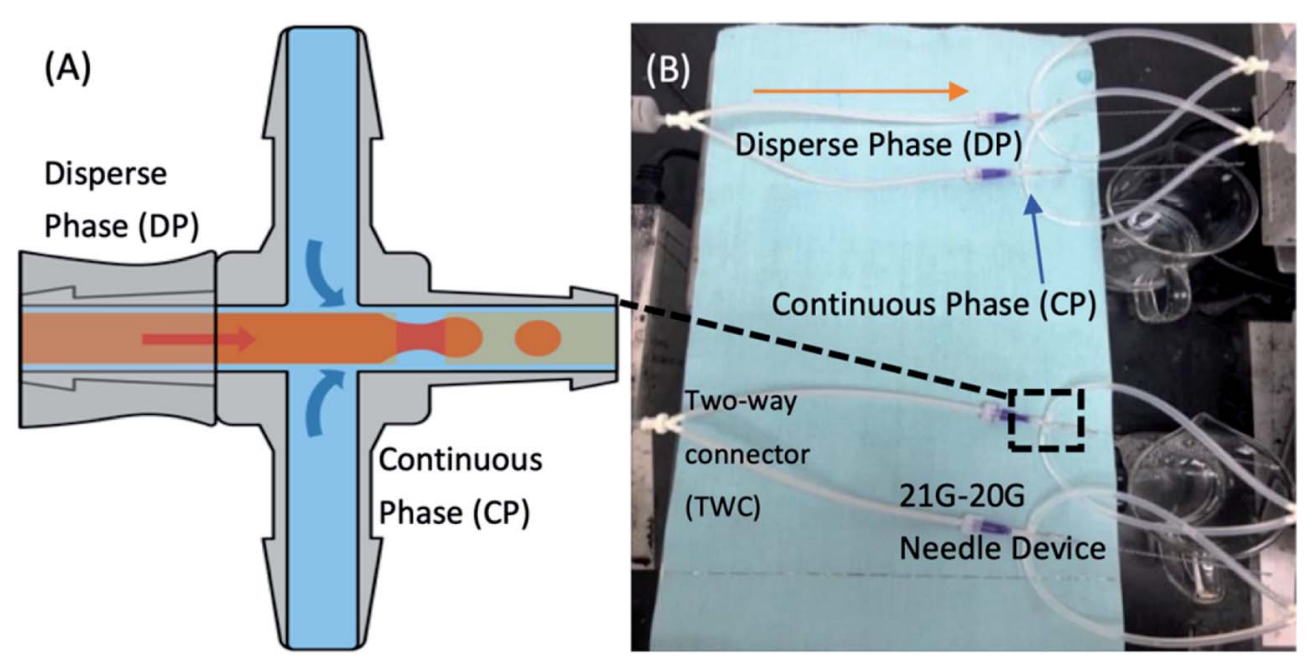

Fig. 1 (A) Schematic illustrations of the microdroplets formation process in co-flowing geometry, where the dispersed phase is PDMS precursor with MWCNTs $/ \mathrm{TiO}_{2}$ fillers and DI water mixed with PVA as the continuous phase (B) needle-based microfluidic droplet generators connected in parallel way for enhanced production rates of PDMS-MWCNTs/TiO 2 microparticles. 
where $\eta$ is the removal efficiency, $C_{0}$ the initial concentration before treatment and $C_{t}$ the concentration after a period of time $t$. This equation is fitted for the calculation of removal efficiency both for sorption and photodegradation. A 500W UV lamp was employed as the light source for the irradiation of the RhB solutions after sorption by PDMS-P, PDMS-M, PDMS-T and PDMS-MWCNTs/TiO 2 (1\% and 2\%) microparticles. After the investigation of the optimum treatment time, the dark balance duration was fixed at 5 hours and UV irradiation duration was fixed at 3 hours, unless a different treatment time is specified. $\mathrm{HCl}, \mathrm{NaOH}$ and benzoquinone (BQ) were purchased from Sigma-Aldrich, China, and isopropyl alcohol (IPA) and ammonium oxalate (AO) were obtained from Sinopharm, China for the following experiments regarding $\mathrm{pH}$ environment and active species identification.

\section{Results \& discussion}

\subsection{Characterization of $\mathrm{MWCNTs} / \mathrm{TiO}_{2}$ nanocomposites}

XRD spectra were collected to characterize the diffraction pattern of the fabricated MWCNTs and MWCNTs $/ \mathrm{TiO}_{2}$ nanocomposites with carbon contents of $5 \mathrm{wt} \%, 10 \mathrm{wt} \%$ and $20 \mathrm{wt} \%$ over $\mathrm{TiO}_{2}$. As indicated in Fig. 2A spectra (a), two key peaks can be seen at $2 \theta=26^{\circ}$ and $43^{\circ}$ for the acid treated MWCNTs. However, when the MWCNTs were loaded with $\mathrm{TiO}_{2}$ (Fig. 2A spectra (b), (c) and (d)) these peaks were reduced, showing that there was no sign for reflection peaks at $2 \theta=26^{\circ}$ and $43^{\circ}$ in the composites and typical reflection peaks of anatase $\mathrm{TiO}_{2}$, for example, (101) $25.3^{\circ}$, (004) $38^{\circ}$, (105) $47.7^{\circ}$, (204) $54.8^{\circ}$, were observed instead. Therefore, this demonstrates that anatase $\mathrm{TiO}_{2}$ is fully deposited onto the surface of MWCNTs during the sol-gel process. TGA was also conducted on these samples to investigate the carbon content. Fig. 2B shows that the MWCNTs were completely decomposed after $600{ }^{\circ} \mathrm{C}$, allowing for the amount titanium in the MWCNTs/TiO 2 nanocomposites to be verified. The results in Fig. 2B suggest that the weight ratio of MWCNTs in the fabricated composites were close to the theoretical calculation, thereby validating the fabrication process of these nanocomposites. Furthermore, it was noted that the different carbon weight ratios could be roughly recognized from the color change of the fabricated composites, as shown in Fig. S2 of the ESI. $\dagger$

The fabricated MWCNTs/ $\mathrm{TiO}_{2}$ were structurally characterized using SEM and TEM, which are shown in Fig. 3 (5\%, 10\% and $20 \%$ carbon contents). Fig. $3 \mathrm{~A}$ and B demonstrate the SEM and TEM images of MWCNTs/ $\mathrm{TiO}_{2}$ nanocomposites with 5\% carbon contents, and Fig. 3C and D for $10 \%$ of carbon contents, Fig. $3 \mathrm{E}$ and $\mathrm{F}$ for $20 \%$, respectively. From the SEM images (Fig. 3A, C and E) it can be seen that the MWCNTs were uniformly covered by a layer of $\mathrm{TiO}_{2}$ after the surfactant wrapping sol-gel method. The surface of the composites is rough due to the presence of $\mathrm{TiO}_{2}$ agglomerated nanoparticles coating the entire surface of the MWCNTs. Fig. 3B, D and F present the TEM images of the composites of $5 \%, 10 \%$ and $20 \%$ carbon contents, respectively, showing that the $\mathrm{TiO}_{2}$ nanoparticles are closely attached onto the surface of the MWCNTs, further validating the surfactant wrapping sol-gel method. The peaks seen in the EDX spectra in Fig. 4G yields additional insight into the chemical composition of the MWCNTs/TiO ${ }_{2}$ nanocomposites, providing evidence for the presence of $\mathrm{C}, \mathrm{O}$ and $\mathrm{Ti}$ elements. Furthermore, it should be noted that the hydrolysis speed is a key parameter to be controlled during the sol-gel process. For instance, a faster dropping speed of the Solution II may result in a rapid hydrolysis of the precursor which is disadvantageous for the even distribution of $\mathrm{TiO}_{2}$ onto the MWCNTs. Therefore, in this experiment, a syringe pump was employed to control the droplet transferring rate by strictly adding Solution II in dropwise manner as $0.5 \mathrm{~mL} \mathrm{~min}^{-1}$.

\subsection{Production of PDMS-MWCNTs/ $/ \mathrm{TiO}_{2}$ microparticles using microfluidics}

The MWCNTs $/ \mathrm{TiO}_{2}$ samples were collected and then employed as nanofiller to mix with the PDMS precursor at weight ratio of $1 \%$ and $2 \%$, respectively, as the dispersed phase in the microfluidic system to form the PDMS-MWCNTs/TiO ${ }_{2}$ in water microdroplets. It is noted that when the weight ratio of
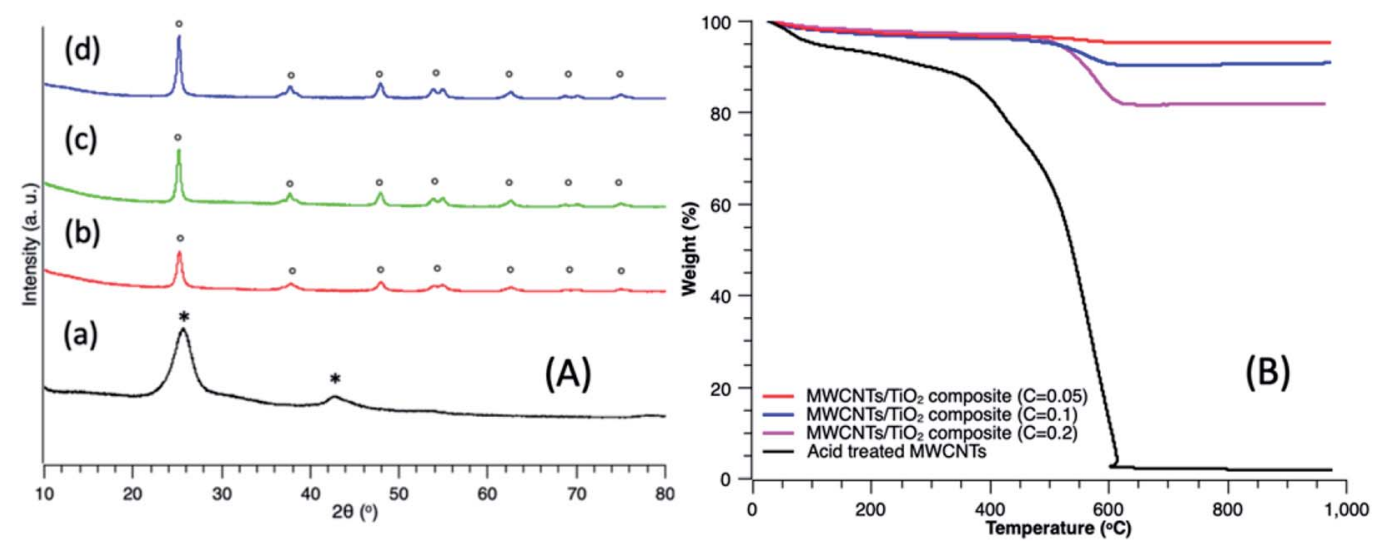

Fig. 2 (A) From spectra (a) to (d) represent X-ray diffraction patterns of acid-treated MWCNTs, MWCNTs/TiO 2 composites with a carbon content of $5 \%, 10 \%$ and $20 \%$, respectively. The peaks that are marked with " $\mathrm{O}$ " and "*" correspond to anatase phase $\mathrm{TiO}_{2}$ and $\mathrm{MWCNTs}$, respectively. (B) TGA data of the acid treated MWCNTs and the $\mathrm{MWCNTs}^{\mathrm{T}} \mathrm{TiO} \mathrm{O}_{2}\left(5 \%, 10 \%\right.$ and $20 \%$ carbon over $\left.\mathrm{TiO}_{2}\right)$. 


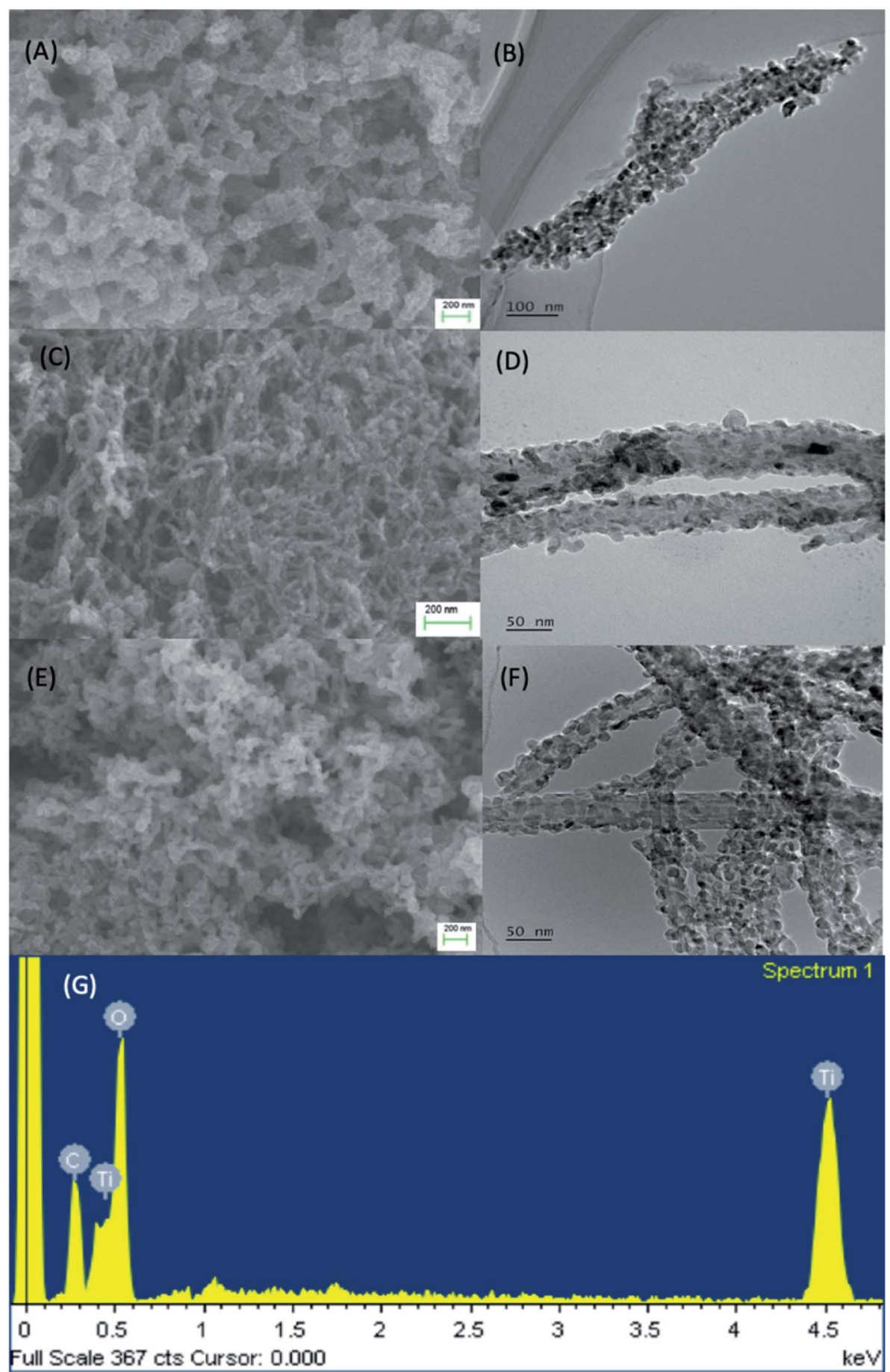

Fig. 3 (A) SEM of MWCNTs/TiO 2 (5\%) nanocomposite, (B) TEM of $M W C N T s / T i O_{2}$ (5\%) nanocomposite and (C) SEM of MWCNTs/TiO 2 (10\%) nanocomposite, (D) TEM of MWCNTs/TiO 2 (10\%) nanocomposite. (E) SEM of MWCNTs/TiO 2 (20\%), (F) TEM of MWCNTs/TiO 2 (20\%) and (G) EDX of $\mathrm{MWCNTs} / \mathrm{TiO}_{2}(20 \%)$.

MWCNTs $/ \mathrm{TiO}_{2}$ raised to $3 \%$, it prevents the formation of droplets, we attribute it to the significant increase in viscosity, which gives rise to higher capillary number. The flow regime in microfluidics can be reflected by dimensionless number, capillary number of the continuous phase and dispersed phase, denoted as $\mathrm{Ca}_{\mathrm{c}}$ and $\mathrm{Ca}_{\mathrm{d}}$, respectively, which both stand for the relative importance between viscous force and interfacial tension as shown in the equation below:

$$
\mathrm{Ca}=\frac{\mu V}{\sigma}
$$

where $\mu, V$ and $\sigma$ represent dynamic viscosity, velocity of fluid phase, and interfacial tension between the two phases. Larger 

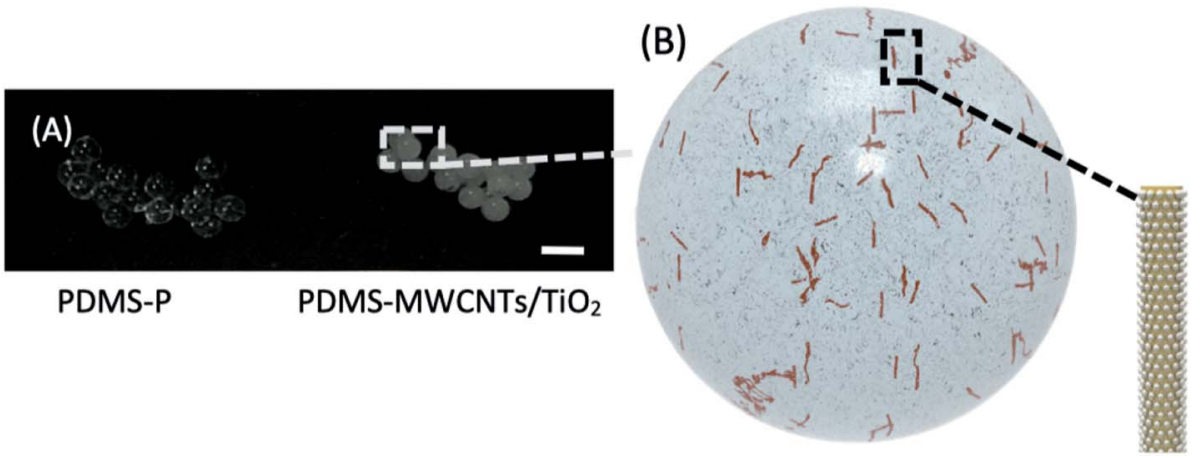

MWCNTs/TiO

Fig. 4 (A) Photos of PDMS-P and PDMS-MWCNTs/TiO 2 microparticles, the particle color turns to grey from transparent after incorporation of MWCNTs $/ \mathrm{TiO}_{2}$, the scale bar in white is $1 \mathrm{~mm}$. (B) Schematic of PDMS-MWCNTs/TiO 2 microparticles, the tube-shaped scatters on the surface of the microparticle are demonstrated as the $\mathrm{MWCNTs} / \mathrm{TiO}_{2}$ nanocomposites as illustrated in the right enlarged image. The white dots represent the $\mathrm{TiO}_{2}$ nanoparticles.

capillary number of the continuous and dispersed phase beyond a critical value can lead to the flow regime transition from dripping to jetting or failure to produce droplets.

According to Huggins equation which relates the viscosity of a polymer solution to the concentration by:

$$
\left[\frac{n_{\mathrm{s}}}{c}\right]=[n]+k_{\mathrm{H}}[n]^{2} c
$$

where $n_{\mathrm{s}}$ is the viscosity of a solution, $[n]$ is the intrinsic viscosity of the solution, $k_{\mathrm{H}}$ is the Huggins coefficient and $c$ is the concentration of the polymer in solution, it suggests that a higher concentration of the polymer could result in a more viscous liquid. To verify the hypothesis, the viscosities of the dispersed phase formed by the PDMS solution added with $1 \%$, $2 \%$ and $3 \% \mathrm{MWCNTs} / \mathrm{TiO}_{2}$ nanocomposites, respectively, were measured by Rotational rheometer (Anton Paar Physica MCR301, Austria). It shows that they possess viscosity of 4.014, 5.296 and 7.1461 Pa s, respectively. Furthermore, we found the particle sediment in the syringe when the ratio of MWCNTs/ $\mathrm{TiO}_{2}$ nanocomposites raised to $4 \%$, which means PDMS could not sustain more MWCNTs/TiO ${ }_{2}$ nanocomposites.

Hence, the stable maximum weight ratio of $\mathrm{MWCNTs} / \mathrm{TiO}_{2}$ was determined to be $2 \%$ in this experiment. As shown in Fig. 4A, the solidified PDMS-MWCNTs/TiO ${ }_{2}$ microparticles displayed a grey color, attributed to the addition of $2 \%$ of MWCNTs $/ \mathrm{TiO}_{2}$ (5\% carbon content). PDMS-P microparticles are included for comparison with PDMS-MWCNTs/TiO 2 (2\%) with a scale bar of $1 \mathrm{~mm}$. A photo of collections of PDMS-MWCNTs/ $\mathrm{TiO}_{2}(2 \%)$ microparticles used in this research could be found in Fig. S3. $\dagger$ Since MWCNTs/TiO ${ }_{2}$ was the only dopants within PDMS-MWCNTs $/ \mathrm{TiO}_{2}$ microparticles, the color change was solely credited to the addition of the nanocomposite. A schematic of PDMS-MWCNTs/TiO ${ }_{2}$ microparticles is depicted in Fig. $4 \mathrm{~B}$, where the spheres on the tube-shaped structure represented as the embedded $\mathrm{TiO}_{2}$ nanoparticles coating the walls of the MWCNTs. The microparticles were flushed by DI water three times before use, in order to fully remove possible residue of PVA which may hinder the sorption of small molecules.

During the microfluidic experiments, PDMS-MWCNTs/TiO microdroplets ( $1 \%$ and $2 \%)$ were collected and captured under an optical microscope, as shown in Fig. 5A and B, respectively. The microdroplets revealed high uniformity, with measured average diameters of $695.6 \mu \mathrm{m}(\mathrm{CV}=1.07 \%)$ and $682.8 \mu \mathrm{m}(\mathrm{CV}$ $=1.15 \%$ ) for $1 \%$ and $2 \%$, respectively. Fig. $5 \mathrm{C}$ and $\mathrm{D}$ present the solidified PDMS-MWCNTs/TiO 2 microparticles with $1 \%$ and $2 \%$ addition, respectively. It was shown that after the solidification of the microdroplets into microparticles the diameters decreased slightly, with measured average diameters of 692.7 $\mu \mathrm{m}(\mathrm{CV}: 0.74 \%)$ and $678.3 \mu \mathrm{m}(\mathrm{CV}: 1.04 \%)$ for $1 \%$ and $2 \%$, respectively. While both the droplets and solids were highly monodispersed, in terms of overall sizes as the $\mathrm{CV}$ values were all less than $1.5 \%$, however, due to the intrinsic agglomeration properties of $\mathrm{TiO}_{2}$, it is inevitable that some scattered clusters are formed within the PDMS substrates, as seen in Fig. 5A and B. Fig. 5E displays the SEM image of a surface of PDMSMWCNTs $/ \mathrm{TiO}_{2} 2 \%$ with a corresponding EDX spectrum in Fig. 5F, confirming the presence of titanium, carbon, silicon, and oxygen elements in the PDMS-MWCNTs/TiO ${ }_{2}$ samples.

\subsection{Sorption of RhB solution using PDMS microparticles}

The removal experiments were performed in batch mode for simulated wastewater that containing RhB. In the removal experiment, several types of PDMS microparticles with similar particle sizes around 680 to $690 \mu \mathrm{m}$ were applied to treat RhB solution. During the dark balance, the RhB molecules primarily overcome the boundary layer of the aqueous phase, conquering the resistance of water. Then, the captured dye molecules could migrate inside the PDMS. Then they would need to overcome the resistance of the interface before moving deeper in the bulk. Molecules that entered the PDMS near the interface has lower concentration than that in the solution. ${ }^{20}$ With stirring conditions, they could constantly diffuse towards the PDMS, pushing the molecules at the interface moving further in the PDMS. The stirring environment could be recognized as a continuous feeding system of RhB for the PDMS to increase molecules contact with the PDMS and from the other side, to accelerate the loss of molecules in the solution. During this process, some of the molecules were adsorbed onto surfaces of nanofillers (MWCNTs, $\mathrm{TiO}_{2}$ and $\mathrm{MWCNTs} / \mathrm{TiO}_{2}$ ). In Fig. 6A, $100 \mathrm{mg}$ of 


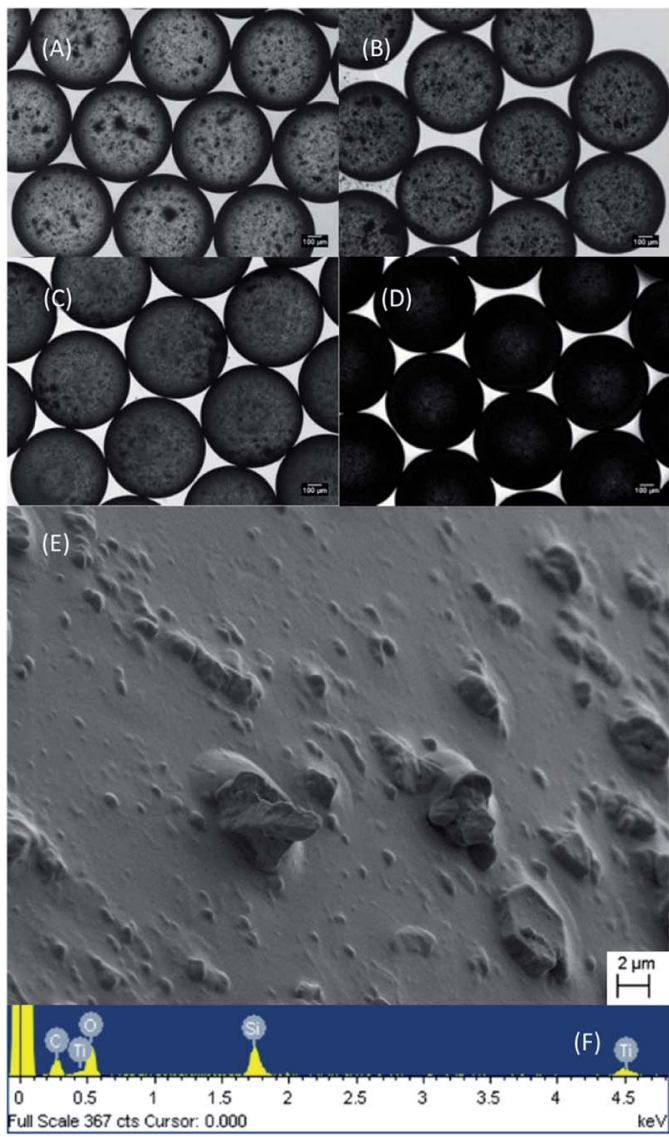

Fig. 5 Optical images of the fabricated PDMS-MWCNTs $/ \mathrm{TiO}_{2}$ microdroplets and the solidified microparticles (A) and (B) for $1 \%,(C)$ and (D) for $2 \%$. (E) SEM image of surface morphology of PDMSMWCNTs $/ \mathrm{TiO}_{2} 2 \%$ microparticle and (F) EDX of PDMS-MWCNTs $/ \mathrm{TiO}_{2}$ $2 \%$ microparticles.

PDMS-MWCNTs/ $/ \mathrm{TiO}_{2} 2 \%$ were soaked into a $10 \mathrm{~mL}$ tube containing $13 \mathrm{mg} \mathrm{L}^{-1} \mathrm{RhB}$ solution. The tube was then transferred into a dark case under stirring of $1000 \mathrm{rpm}$. Sampling and analytical measurement were carried out in $30 \mathrm{~min}, 1 \mathrm{~h}, 2 \mathrm{~h}, 3 \mathrm{~h}$, $4 \mathrm{~h}, 5 \mathrm{~h}, 10 \mathrm{~h}$ and $24 \mathrm{~h}$. Fig. 6A indicates that the obvious removal of RhB occurred in the first 5 hours after which gradually reached to a constant value close to saturation. Further increasing the treatment time to $10 \mathrm{~h}$ and $24 \mathrm{~h}$ could not obtain significant removal results. In spite of sorption, photocatalytical activities did not happen because of no irradiation in this stage. Mass loading from $100 \mathrm{mg}$ to $1000 \mathrm{mg}$ with increasing of every $100 \mathrm{mg}$ were used to treat $10 \mathrm{~mL} \mathrm{RhB} \mathrm{solu-}$ tion of $13 \mathrm{mg} \mathrm{L}^{-1}$, given a five-hour sorption time. The results from Fig. 6B reveal that larger mass of microparticles released, more contaminants could be removed. Because more particles could provide larger numbers of available contact sites, allowing more target pollutants to attach. As can be seen from the data, $100 \mathrm{mg}$ PDMS-MWCNTs/TiO ${ }_{2}$ microparticles could only reduce less than $10 \%$ of the concentration. The removal efficiency gradually increased with more sorbents dipped, for instance, around $20 \%$ removal efficiency was achieved by $400 \mathrm{mg}$ particles, and 45\% removal was realized by $900 \mathrm{mg}$.
Although the removal efficiency did not show significant enhancement from $500 \mathrm{mg}$ to $900 \mathrm{mg}$, the sorption for such number of particles required more time to reach sorption and desorption equilibrium. This was validated based on the case of $1000 \mathrm{mg}$ microparticles that $77 \%$ of dye was removed after a $24 \mathrm{~h}$ sorption. Although the dark balance time needs to be ensured, 24 hours can be too long for some engineering projects. According to the results above, overall, the dark time for sorption was recognized as five hours in order to ensure a stable sorption of pollutants to be reached.

$500 \mathrm{mg}$ of PDMS-P, PDMS-T, PDMS-M and PDMS-MWCNTs/ $\mathrm{TiO}_{2}$ (1\% and $2 \%$, both used $5 \%$ carbon content of MWCNTs/ $\mathrm{TiO}_{2}$ ) were loaded into $10 \mathrm{~mL}, 13 \mathrm{mg} \mathrm{L}^{-1} \mathrm{RhB}$ solution. The dark time for sorption balance was allowed to be five hours and stirring at $1000 \mathrm{rpm}$. In Fig. 6C, the peaks from UV-Vis spectrometry represent the contaminant left after five hours dark balance. Based on the intensity of the RhB solution detected, PDMS-P had the most limited removal efficiency and following by PDMS-T, PDMS-M, PDMS-MWCNTs/TiO ${ }_{2}$ 1\% and PDMSMWCNTs $/ \mathrm{TiO}_{2} 2 \%$. Although PDMS was able to absorb organic molecules due to its hydrophobic property, it takes longer time to perform sorption and desorption equilibrium for this mass loading of microparticles. Quantitative analysis results from the UV-Vis spectrometry results suggested that $7.7 \%$ of removal efficiency was realized by PDMS-P in 5 hours, reducing only $1 \mathrm{mg} \mathrm{L}^{-1}$ of concentration. This low efficiency was attributed to the smooth and compact surface of the pristine PDMS. Additionally, unlike other organics that are highly soluble in PDMS such as diisopropylamine, tetrachloromethane, hexane, acetate, chloroform and toluene, the octanol-water partition coefficient for RhB is approximately 89 which is relatively lower than the compounds mentioned above. ${ }^{20}$ Nanofillers could alter surface property of the substrates through their own surface properties, hydrophilic or hydrophobic, as well as the modification of surface roughness. ${ }^{50}$ In addition, carbonaceous materials could normally increase the sorption efficiency due to the hydrophobic properties, van-der Waals interaction forces, hydrogenboding interactions, $\pi-\pi$ stackings and electrostatic and dispersion interactions. Therefore, PDMS-M achieved a higher removal efficiency (app. 23\%) than PDMS-P, as can be seen in Fig. 6C. PDMS-T also performed a higher sorption efficiency (app. 15.4\%) than PDMS-P, as a result of dispersion of $\mathrm{TiO}_{2}$ into PDMS, validating that the $\mathrm{TiO}_{2}$ nanofillers could boost the sorption efficiency. ${ }^{40,51}$ For PDMS-MWCNTs/TiO ${ }_{2}$, it was found that higher MWCNTs/TiO 2 density used in PDMS substrates, higher efficiency was finally achieved, as can be seen in Fig. 6C that the efficiencies are $23 \%$ and $38.5 \%$ for PDMS-MWCNTs/ $\mathrm{TiO}_{2} 1 \%$ and $2 \%$, respectively. This is because aggregations of nanoparticles are in favor of hydrophobicity and concentration increasement of nanoparticles tends to improve irregularity of the surface morphology, ${ }^{52}$ as shown in Fig. $5 \mathrm{E}$.

\subsection{Photodegradation of RhB solution using PDMS microparticles}

Fig. 7A illustrates the residual concentration of RhB solution after photodegradation by PDMS-P, PDMS-M, PDMS-T and 

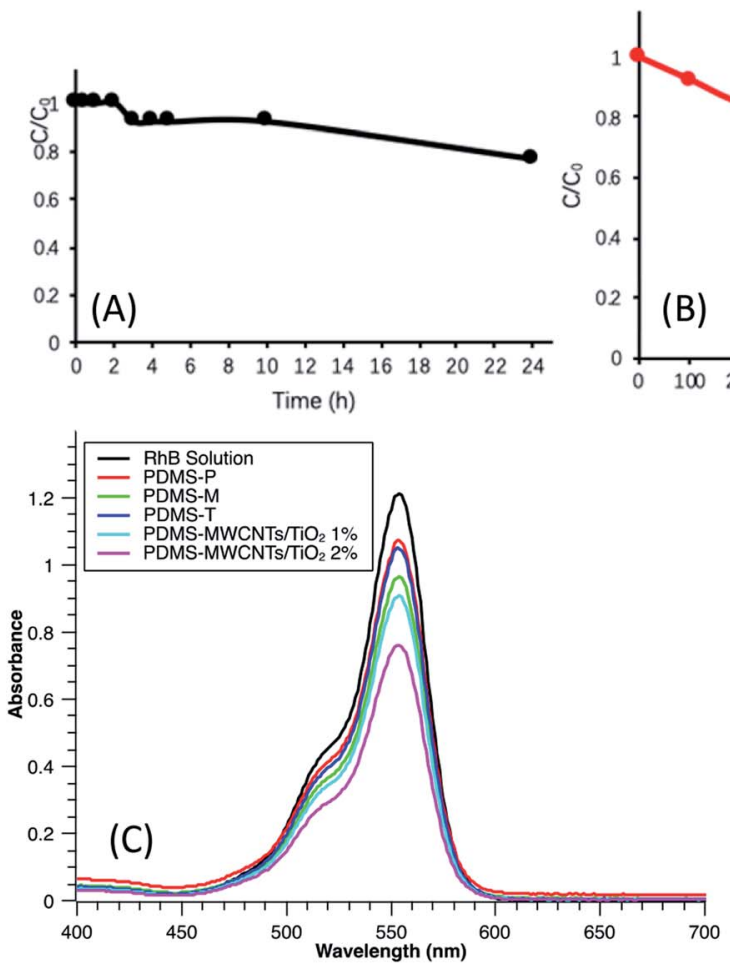

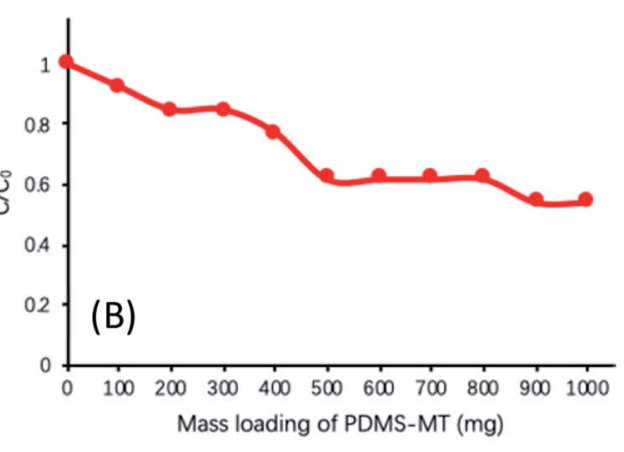

Fig. 6 (A) Sorption of RhB in $24 \mathrm{~h}$ PDMS-MWCNTs/TiO 2 (2\%). (B) Sorption of RhB by PDMS-MWCNTs/TiO 2 (2\%) with mass loadings from 100 mg to $1000 \mathrm{mg}$. (C) Sorption of RhB by different types of PDMS microparticles.

PDMS-MWCNTs $/ \mathrm{TiO}_{2}(1 \%$ and $2 \%)$ microparticles. From the peaks of RhB residual, it could be seen that PDMS-MWCNTs/ $\mathrm{TiO}_{2}(2 \%)$ performed the highest removal efficiency among all types of PDMS microparticles. A control group of RhB solution without any addition of PDMS or catalyst remained an unchanged concentration throughout the whole treatment. As expected, PDMS-P and PDMS-M did not show photocatalytic activity due to the absence of photocatalyst, so the reduction of the peak intensity was solely attributed to the continuous sorption by the microparticles in this period of time.

However, since it is difficult to exclude the sorption behavior of PDMS microparticles during the photocatalytic activity, this is a synergetic process that includes constant sorption and photodegradation. It should be noted that when RhB molecules were photocatalytic oxidized, the contact sites would be available to accept more RhB. Also, thanks to the optic properties, PDMS is transparent so that allowing lights passing through the substrates. Therefore, sorption could persistently contribute to the reduction of the compound concentration. Table 1 lists the calculated sorption efficiency and concentration values after dark balance (short for SO), the treatment efficiency of synergetic effect in the $3 \mathrm{~h}$ irradiation period (short for SY, includes the sorption (SO) and photodegradation (PD) in this period) and the overall removal efficiency based on the final reactant concentration in the solutions. PDMS-P reached $23 \%$ overall removal efficiency in the following three hours which was similar with what PDMS-M achieved in the dark balance time. Since there were no photocatalysis in these two kinds of microparticles, the removal was achieved only attributed to the sorption. Because the same mass of particles was released and the sorption took place under identical conditions, it could be speculated that the nanofiller, MWCNTs, only acted as a role to speed up the sorption process of small molecules into the PDMS bulk. For other PDMS microparticles, based on the concentration variance during the irradiation, it could be found that PDMS-T presented a lower efficiency than PDMS-MWCNTs/ $\mathrm{TiO}_{2} \quad 1 \%$ and much lower than PDMS-MWCNTs/TiO 2 2\%. Considering the whole process, PDMS-MWCNTs/TiO ${ }_{2} 2 \%$ degraded $85 \%$ of the organic compounds in total, bringing down the concentration from $13 \mathrm{mg} \mathrm{L}^{-1}$ to $2 \mathrm{mg} \mathrm{L}^{-1}$ which was $45 \%$ higher than PDMS-T microparticles. Fig. S4 $\uparrow$ displays the color change after the synergetic treatment by those PDMS, and the decoloration effect by PDMS-MWCNTs/TiO $2 \%$ was more evident than other groups. MWCNTs played an important supporting role as an electron acceptor for $\mathrm{TiO}_{2}$ in PDMS$\mathrm{MWCNTs} / \mathrm{TiO}_{2}$ to prevent the recombination of electron-hole to some extent, which was beneficial from the conductive structure of MWCNTs. This also explained that PDMS-MWCNTs/ $\mathrm{TiO}_{2}$ 1\% had improved photodegradation performance with overall enhancement of $15 \%$ than PDMS-T microparticles, which was $38.5 \%$. From the results, it could be also speculated that PDMS-MWCNTs $/ \mathrm{TiO}_{2}$ promoted a higher electron transferring efficiency and reducing the electron-hole pair recombination rate than that of PDMS-T. Noted that PDMS is nonconductive which is not constructive for the electron transferring, leaving PDMS-T in an adverse position during the photodegradation. On the other side, PDMS-MWCNTs $/ \mathrm{TiO}_{2} 2 \%$ facilitated more generation of the free radicals and induced 

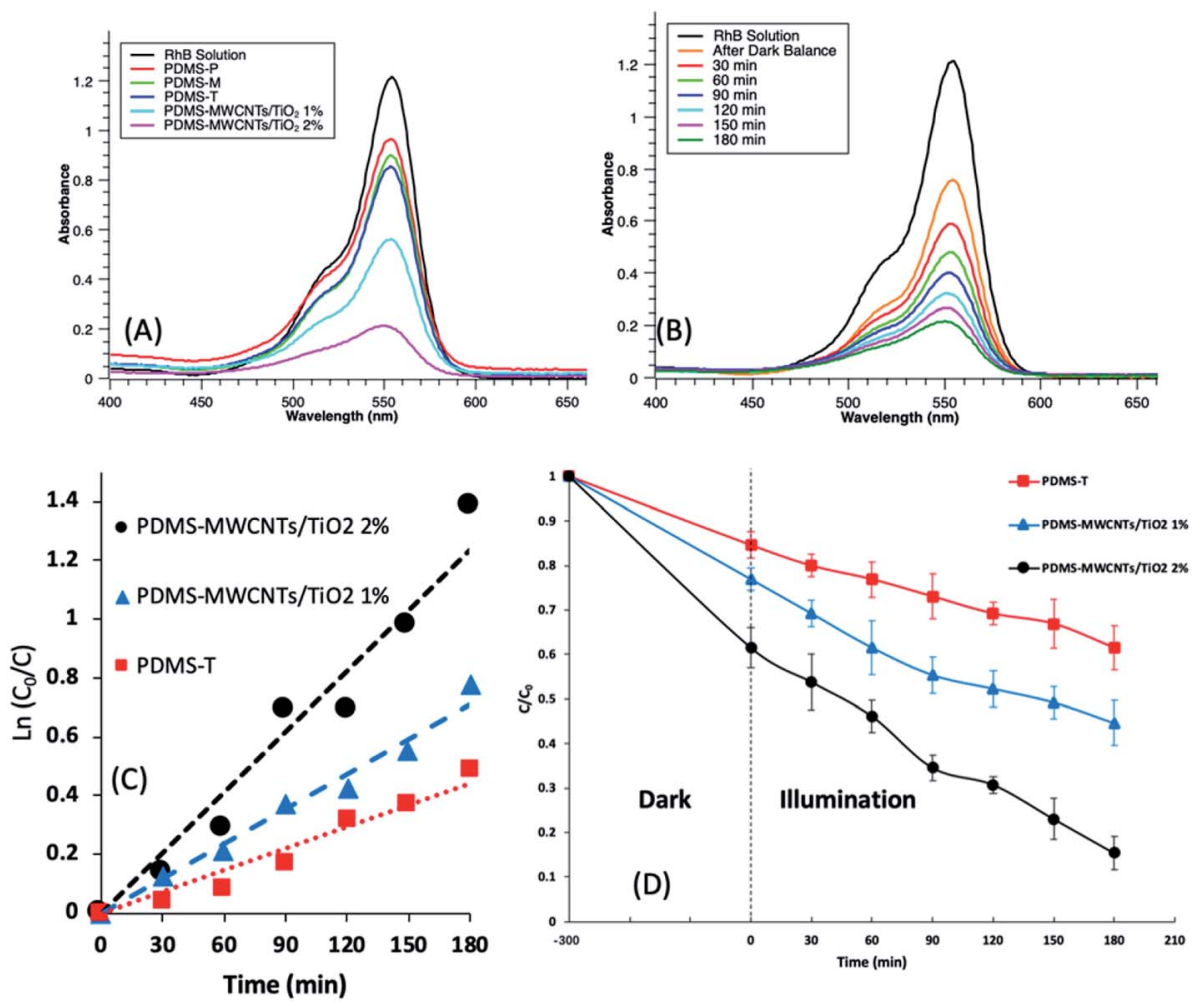

Fig. 7 (A) Photo-degradation of RhB by different types of PDMS microparticles. (B) Photo-degradation of RhB in 180 min using PDMS-MWCNTs/ $\mathrm{TiO}_{2}(2 \%)$ with dark balance and (C) photodegradation kinetics of RhB by PDMS $-\mathrm{MWCNTs} / \mathrm{TiO} 22 \%$, PDMS $-\mathrm{MWCNTs} / \mathrm{TiO} 21 \%$ and PDMS-T. The calculated reduction rate constant of PDMS $-\mathrm{MWCNTs}_{\mathrm{TiO}} 2 \%, \mathrm{PDMS}-\mathrm{MWCNTs}_{2} / \mathrm{TiO}_{2} 1 \%$ and PDMS-T are $69 \times 10^{-4} \mathrm{~min}^{-1}, 39 \times 10^{-4} \mathrm{~min}^{-1}$ and $25 \times 10^{-4} \mathrm{~min}^{-1}$, respectively. (D) Decolorization rate curves of RhB by PDMS $-\mathrm{MWCNTs}_{\mathrm{TTiO}} 2 \%, \mathrm{PDMS}-\mathrm{MWCNTs} / \mathrm{TiO} \mathrm{O}_{2} \mathrm{1} \%$ and PDMS-T microparticles.

Table 1 Treatment efficiency and concentration variance by various PDMS microparticles

\begin{tabular}{|c|c|c|c|c|c|}
\hline & $C_{\left(\mathrm{so}, \mathrm{mg} \mathrm{L}^{-1}\right)}$ & $\mathrm{AB}_{(\%)}$ & $C_{\left(\text {Final, } \mathrm{mg} \mathrm{L}^{-1}\right)}$ & $\left.\mathrm{SY}_{(\mathrm{SO}+\mathrm{PD}}, \%\right)$ & $R_{(\text {Overall, \%) }}$ \\
\hline $\mathrm{RhB}$ & 13 & 0 & 13 & 0 & 0 \\
\hline PDMS-P & 12 & 7.7 & 10 & 16.7 & 23.1 \\
\hline PDMS-T & 11 & 15.4 & 8 & 27.3 & 38.5 \\
\hline PDMS-MWCNTs/TiO 2 1\% & 10 & 23.1 & 6 & 40 & 53.8 \\
\hline PDMS-MWCNTs/TiO 2 2\% & 8 & 38.5 & 2 & 75 & 84.6 \\
\hline
\end{tabular}

a stronger oxidation process than other types of PDMS microparticles based on the results.

$500 \mathrm{mg}$ of PDMS-T, PDMS-MWCNTs/TiO 2 1\%, PDMSMWCNTs/TiO $2 \%$ were immersed into $10 \mathrm{~mL} 13 \mathrm{mg} \mathrm{L}{ }^{-1} \mathrm{RhB}$ solutions under dark balance and irradiation, with sampling and concentration measured every $30 \mathrm{~min}$. Fig. 7B demonstrates the peaks of RhB solution treated by PDMS-MWCNTs/ $\mathrm{TiO}_{2} 2 \%$ microparticles from 30 to $180 \mathrm{~min}$. As can be seen, the concentration of the compounds declined with irradiation time that nearly half of the pollutants were treated in $90 \mathrm{~min}$ and over $75 \%$ of dyes was degraded in $180 \mathrm{~min}$. According to the dye concentration at each time point, kinetics plots of PDMS-T, PDMS-MWCNTs/TiO 2 1\%, PDMS-MWCNTs/TiO $2 \%$ were shown in Fig. 7C. The lines show that the reaction rate changes are a linear function against the treatment time. So, the photocatalytic reaction could be expressed as pseudo-first order kinetics followed Langmuir-Hinshelwood model, ${ }^{53,54}$

$$
\ln \left(C_{0} / C\right)=k_{\mathrm{a}} t
$$

Here $C_{0}$ is the concentration value after the sorption equilibrium, $C$ is the dye concentration at each sampling time point, $k_{\mathrm{a}}$ is the apparent reaction rate constant for dye degradation and $t$ is the reaction time. Here the calculated reduction rate constant of PDMS-MWCNTs/TiO $2 \%$ is $69 \times 10^{-4} \mathrm{~min}^{-1}$ which is higher than that of PDMS-T of $25 \times 10^{-4} \mathrm{~min}^{-1}$ and PDMS-MWCNTs/ $\mathrm{TiO}_{2} 1 \%$ of $39 \times 10^{-4} \mathrm{~min}^{-1}$. In Fig. 6D, the curves of the decolorization rates of $\mathrm{RhB}$ with time are shown for these three 

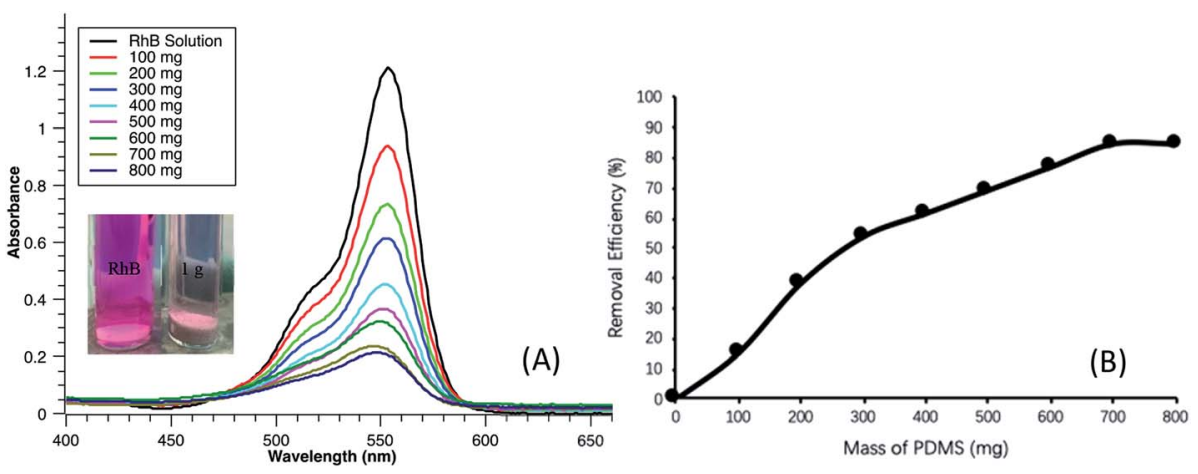

Fig. 8 (A) Photo-degradation of RhB by PDMS-MWCNTs/TiO 2 (2\%) with mass loadings from $100 \mathrm{mg}$ to 800 mg $3 \mathrm{~h}$ irradiation without dark balance time and (B) the calculated treatment efficiencies.

types of PDMS microparticles, covering the whole treatment process from the dark balance to the end of photodegradation.

During the photocatalytic reaction period, dye molecules were constantly decomposed and reaction sites of $\mathrm{TiO}_{2}$ were thus continuously recovered which were available for the continuous uptake of the dye molecules. The photodegradation process slowly reached to an equilibrium and was reflected by the apparent reaction rate constant as mentioned above. In the next part of experiment, there was no dark balance time, but only irradiation was implemented for variant mass loading of PDMS-MWCNTs/ $/ \mathrm{TiO}_{2} 2 \%$. Fig. 8A depicts the peaks of $\mathrm{RhB}$ treated by the PDMS microparticles after three hours of irradiation, for dealing with the same batch of dye pollutants as 10 $\mathrm{mL}, 13 \mathrm{mg} \mathrm{L}^{-1} \mathrm{RhB}$ solution, and the removal efficiencies were calculated and shown in the Fig. 8B. From the intensity of absorbance, it could be seen that more particles could enable more dyes to be photodegraded, as expected. For example, $800 \mathrm{mg}$ could lower the dye concentration from $13 \mathrm{mg} \mathrm{L}^{-1}$ to $2 \mathrm{mg} \mathrm{L}^{-1}$ in three hours, whereas $100 \mathrm{mg}$ only achieved around $15 \%$ efficiency. Inset of Fig. $8 \mathrm{~A}$ is a color comparison of RhB solution without any addition of catalyst and with $1000 \mathrm{mg}$ of PDMS-MWCNTs $/ \mathrm{TiO}_{2} \quad 2 \%$ microparticles after photodegradation. The pink color almost vanished after illumination and there was no RhB detected from the water sample in this case. The dark balance time is a significant stage for highly efficient treatment, although it is challenging to examine photocatalytic reactions separately from the sorption. For instance, given a dark balance time of 5 hours, $500 \mathrm{mg}$ PDMS-MWCNTs/ $\mathrm{TiO}_{2} 2 \%$ microparticles were capable of reaching a similar efficiency to that of $800 \mathrm{mg}$ without the dark balance time. Owing to the uniformity of particles generated by microfluidics, it is possible to estimate the mass loading of particles required prior to each treatment and thus saving raw materials based on the calculation. Because microfluidics is highly controllable in terms of the composition, amount and size for droplet generation, it is also advantageous to tailor functionalized microparticles according to different needs.

The photodegradation of $\mathrm{RhB}$ were attributed to the destruction of benzene ring of $\mathrm{RhB}$ molecules because of effective cleavage of the conjugated chromophore structure ( $\mathrm{C}=\mathrm{O}$ and $\mathrm{C}=\mathrm{N}$ bonds). This could be verified from the decreasing of the maximum absorption peak at $554 \mathrm{~nm}$ with a blue shift, as shown in Fig. 9A, and the color of the solution stepwise faded in the liquid phase. N-Deethylation also occurred at the wavelength of $259 \mathrm{~nm}$ with the maximum absorption peak declined. ${ }^{55}$ Three common active oxidant species, hydroxyl radicals $(\cdot \mathrm{OH})$, superoxide radical $\left(\cdot \mathrm{O}_{2}{ }^{-}\right)$and photogenerated hole $\left(\mathrm{h}^{+}\right)$could be verified during the photocatalytic reactions by employing scavengers or trapping agents isopropyl alcohol (IPA), benzoquinone (BQ) and ammonium
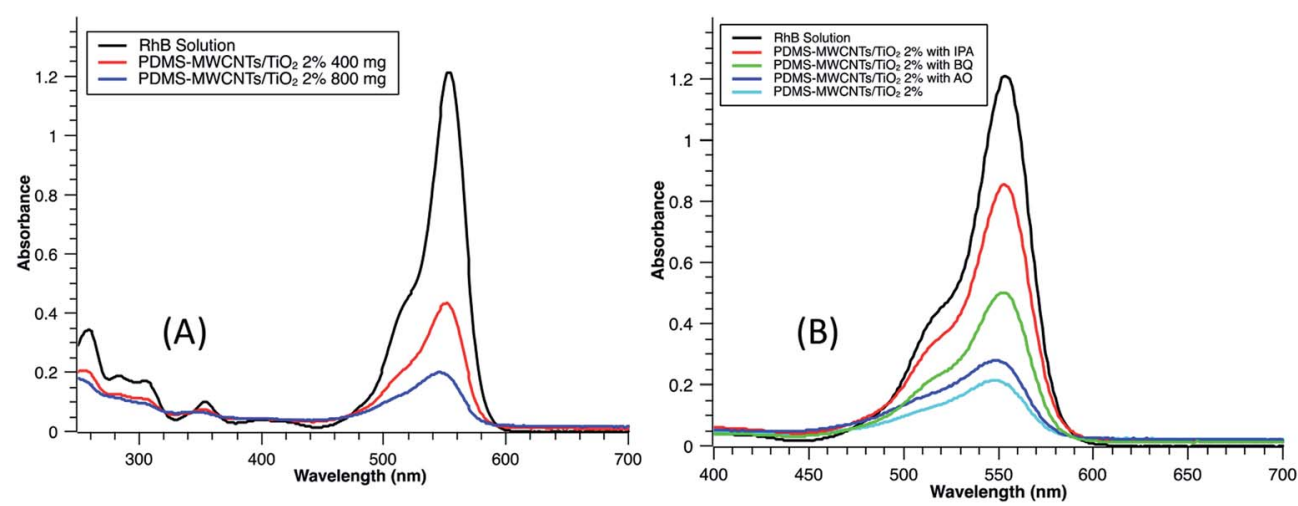

Fig. 9 (A) Photo-degradation of RhB by PDMS-MWCNTs/TiO $(2 \%)$ with mass loadings of $400 \mathrm{mg}$ and 800 mg for investigation of degradation mechanisms (B) RhB degradation by PDMS-MWCNTs/TiO 2 (2\%) with trapping agents. 


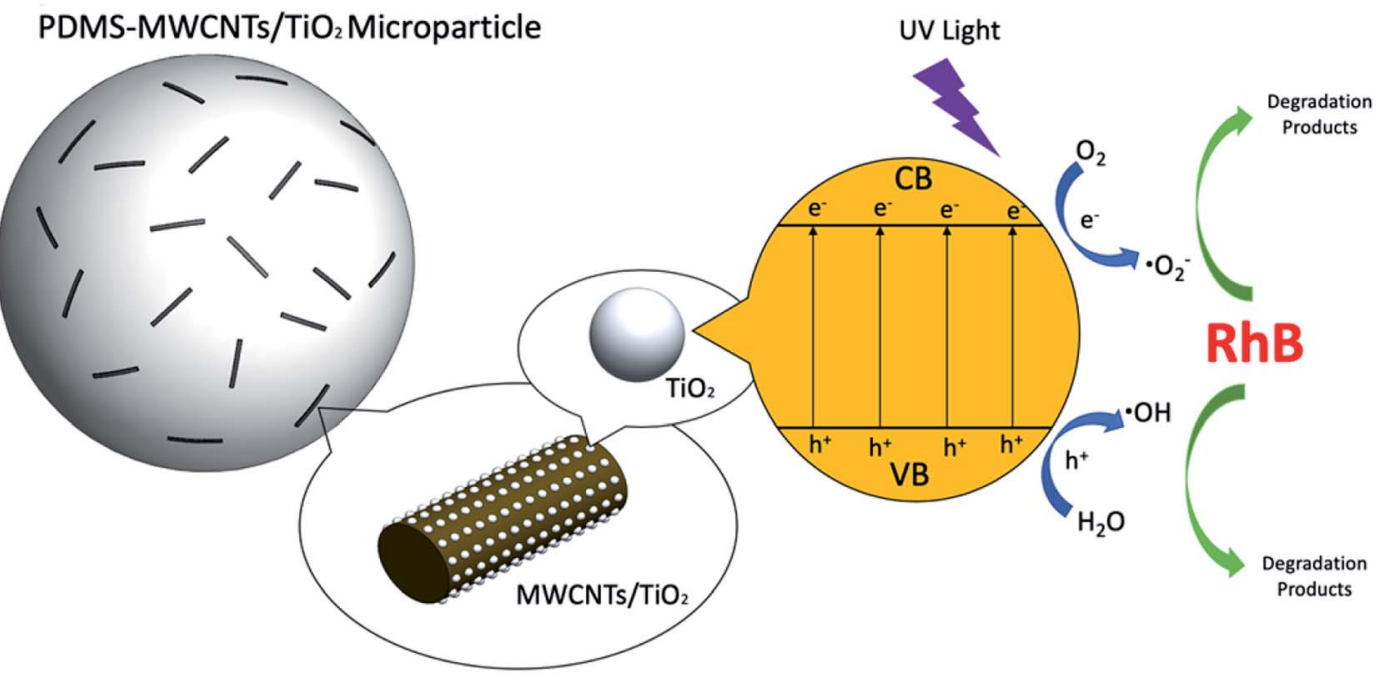

Fig. 10 Schematic of photodegradation process of RhB by PDMS-MWCNTs/TiO $\mathrm{T}_{2}$ microparticles under UV irradiation.

oxalate (AO), respectively, during photocatalytic reactions. ${ }^{56,57}$ In this experiment, three groups of $800 \mathrm{mg}$ PDMS-MWCNTs/TiO $2 \%$ microparticles were released to treat $\mathrm{RhB}$ solutions with the addition of IPA, BQ, AO, respectively. Fig. 9B demonstrates the $\mathrm{RhB}$ residual in solution after three hours treatment with the capture agents. It could be seen that the addition of AO only had slight effects on the degradation efficiency compared with the blank group, indicating the photogenerated hole $\left(\mathrm{h}^{+}\right)$had limited impact to the reaction. However, with IPA and BQ, the photodegradation efficiency against $\mathrm{RhB}$ decreased significantly, implying both $\cdot \mathrm{OH}$ and $\cdot \mathrm{O}_{2}{ }^{-}$had important contribution to the reaction and acted as the main reactive species during the photodegradation. Based on this, a photodegradation mechanism of $\mathrm{RhB}$ by $\mathrm{PDMS}-\mathrm{MWCNTs} / \mathrm{TiO}_{2}$ microparticles is schematically illustrated in Fig. 10.

The sorption and photodegradation processes of $\mathrm{RhB}$ could be influenced by $\mathrm{pH}$ of the aqueous environment. The initial concentration was $13 \mathrm{mg} \mathrm{L}^{-1}$ for all the testing groups and treatment results are listed in Table 2. $C_{\mathrm{SO}}$ denotes for the concentration of $\mathrm{RhB}$ in the liquid phase after dark balance with PDMS-MWCNTs $/ \mathrm{TiO}_{2} 2 \%$ microparticles. $\mathrm{NaOH}$ and $\mathrm{HCl}$ were applied for preadjusted $\mathrm{RhB}$ solutions with $\mathrm{pH}$ values between 3.0 and 12.0. The pH values mainly affected surface electronic properties, catalyst adsorption characteristics and the state of dye molecules, as a result of protonation of the amine

Table 2 RhB concentrations variance after dark balance and irradiation under different $\mathrm{pH}$ environment with initial concentration of $13 \mathrm{mg} \mathrm{L}^{-1}$

\begin{tabular}{lll}
\hline $\mathrm{pH}$ & $C_{\left(\mathrm{SO}, \mathrm{mg} \mathrm{L}^{-1}\right)}$ & $C_{\left(\mathrm{Final}, \mathrm{mg} \mathrm{L}^{-1}\right)}$ \\
\hline 3 & 10 & 6 \\
5 & 8 & 3 \\
7 & 8 & 2 \\
9 & 7 & 1 \\
12 & 10 & 4
\end{tabular}

functionalities within RhB molecules. ${ }^{58,59}$ In the acidic media, chemisorption dominates the process due to the cationic form of RhB in this environment. In addition, the sorption process could be restrained due to the presence of $\mathrm{H}^{+}$ions, and electropositive charge is not profitable for the photodegradation process of RhB. ${ }^{59}$ The sorption efficiency of PDMS-MWCNTs/ $\mathrm{TiO}_{2}$ increases with $\mathrm{pH}$ values varying from 3 to 9 during which chemisorption (MWCNTs/TiO ${ }_{2}$ on PDMS-MWCNTs/TiO surface) and physisorption (PDMS) had coaction for the uptake of RhB. Meanwhile, RhB is in the zwitterionic form when raising $\mathrm{pH}$ values and this could lead to an aggregation to larger molecular forms of the molecules, so-called dimer, which is beneficial for a more efficient removal by PDMS. ${ }^{60}$ Additionally, alkaline media could facilitate the easy generation of $\mathrm{OH}^{*}$ radicals during the photodegradation. However, alkaline media such as $\mathrm{pH}=12$ adversely impacted the uptake of molecules as physisorption dominate under this condition. Hence, the results were limited by the environment although carbonaceous materials owned polarizability which could enhance the physisorption due to the $\pi$ cloud.

Table 3 lists RhB solutions with variant initial concentrations from $4 \mathrm{mg} \mathrm{L}^{-1}$ to $19 \mathrm{mg} \mathrm{L}^{-1}$ and their treatment efficiency after the sorption and photodegradation. The data implies that higher initial concentration is favorable for the uptake of more dyes

Table 3 RhB removal by different initial concentration using $100 \mathrm{mg}$ PDMS-MWCNTs/TiO 2 (2\%), after sorption in dark following photodegradation

\begin{tabular}{lll}
\hline$C_{\left(0, \mathrm{mg} \mathrm{L}^{-1}\right)}$ & $C_{\left(\mathrm{SO}, \mathrm{mg} \mathrm{L}^{-1}\right)}$ & $C_{\left(\mathrm{Final}, \mathrm{mg} \mathrm{L}^{-1}\right)}$ \\
\hline 19 & 17 & 13 \\
16 & 14 & 11 \\
13 & 12 & 9 \\
10 & 9 & 6 \\
7 & 6 & 3 \\
4 & 3 & 1
\end{tabular}


under a given time. Although as mentioned above, the total removal amount was dependent on the mass of sorbents submersed in the liquid phase, more concentrated solution occupied higher mass gradient between RhB solution and microparticles, and thus, owing to a larger driving force for dye molecules transferring to the microparticles. In other words, they were easier to get rid of the resistance of the liquid to PDMS. On the other hand, lower initial concentration of molecules, eventually was negative for the contaminants to be removed rapidly by PDMS, as can be seen from the $7 \mathrm{mg} \mathrm{L}^{-1}$ and $4 \mathrm{mg} \mathrm{L}^{-1}$ groups. However, if the sorption reached to the equilibrium first, similar concentrations decline was found during the photocatalytic process. This suggests that the sorption process may domain the overall treatment process. The reduction of concentrations during irradiation also supported the effective synergetic removal of RhB by PDMS-MWCNTs/TiO 2 . In addition, the PDMS-MWCNTs/TiO $2 \%$ microparticles with $10 \%$ and $20 \%$ carbon content of MWCNTs/TiO $/ 2$ nanocomposites were fabricated and tested in the same fashion. The overall removal efficiencies for those two types of PDMS-MWCNTs/TiO $2 \%$ microparticles were around 69\% and $62 \%$, respectively which were lower than the $5 \%$ carbon contents group.

\subsection{Recycling and reuse of PDMS-MWCNTs/TiO $2 \%$ microparticles}

One of the merits to integrate $\mathrm{MWCNTs} / \mathrm{TiO}_{2}$ nanocomposites with PDMS by microfluidics is to immobilize the nanopowders to avoid serious agglomerations, and to prevent catalyst loss and secondary pollutions to the aqueous environment. Meanwhile, the micro-scaled particles are easier to be recycled and reused than nanocomposites. Since the diffusion speed of RhB in PDMS is not high, thick and bulk PDMS substrate might lead to a waste of the materials. The microscale of PDMS could remove dye molecules in a more rapid manner due to the larger surface areas with the help of stirring. PDMS microparticles could elute out the residual RhB and get recovered by flushing with water and exposing to light. The overall treatment efficiency of PDMS-MWCNTs/ $/ \mathrm{TiO}_{2}$ microparticles could remain round $70 \%$ after three times of recycling and reuse.

\section{Conclusions}

MWCNTs/TiO 2 nanocomposites were fabricated using the surfactant wrapping sol-gel method. The nanocomposites were characterized by a variety of analytical and morphological characterization techniques including XRD, TGA, SEM, EDX and TEM to confirm the controlled formation of $\mathrm{TiO}_{2}$ nanoparticles on the surface of MWCNTs. MWCNTs/TiO 2 nanocomposites were subsequently employed as a nanofiller to mix with PDMS precursor with a $1 \%$ and $2 \%$ weight ratio, respectively. The mixture was utilized as the dispersed phase for the needle-based microfluidic devices, with flow rates of the dispersed and continuous phase at 30 and $200 \mu \mathrm{L} \mathrm{min}^{-1}$, respectively, to form PDMS-MWCNTs/ $/ \mathrm{TiO}_{2}$ microdroplets, which were then thermally solidified to microparticles. The average diameters of the particles were $692.7 \mu \mathrm{m}$ (CV: 0.74\%) and $678.3 \mu \mathrm{m}$ (CV: 1.04\%) for PDMS-
MWCNTs $/ \mathrm{TiO}_{2} 1 \%$ and 2\%, respectively. Other PDMS microparticles including PDMS-P, PDMS-M, PDMS-T were also generated in this fashion. The microparticles were applied to treat Rhodamine B solutions via sorption and photodegradation processes. $500 \mathrm{mg}$ of PDMS microparticles incorporating $2 \mathrm{wt} \%$ MWCNTs/ $\mathrm{TiO}_{2}$ nanocomposites can sorb $38.5 \%$ of $\mathrm{RhB}$ in 5 hours in dark environment. After the dark balance time, RhB was continuously photodegraded under UV irradiation for three hours and eventually around $85 \%$ overall treatment efficiency could be realized. The photodegradation process fit well with pseudo-first order kinetics, following Langmuir-Hinshelwood model. Furthermore, it was found that the highest overall treatment efficiency was achieved under an alkaline environment of $\mathrm{pH}$ 9. In addition, higher initial pollutant concentration was of advantage for more efficient treatment. The microparticles are efficient and environmentally compatible, and also exhibit promising synergetic treatment capabilities for the sorption and photodegradation of target pollutants even after being recycled and reused for three times.

\section{Author contributions}

YR, JH, GZC and ZL proposed the research and designed the experiments, ZL and CW conducted the experiments, ZL and YR wrote the manuscript, FL and BG contributed to the photocatalytic experiment, KSK contributed to the microfluidic experiment, FL, BG, YC, JW, JH, GZC, KSK, YS and YY reviewed the manuscript and provided suggestions.

\section{Conflicts of interest}

The authors declare that there is no conflict of interest.

\section{Acknowledgements}

This research was supported by National Natural Science Foundation of China under Grant No. 51981240009, Zhejiang Provincial Natural Science Foundation of China under Grant No. LY19E060001 and LQ19F050003. The work was also supported by Ningbo Science and Technology Bureau under Service Industry Science \& Technology Programme with project code 2019F1030, Ningbo Science and Technology Bureau Technology Innovation Team under Grant No. 2016B10010 and 2017C510001, Shenzhen Basic Research Program under Grant No. JCYJ20190808144813101, as well as Research Seed and Supplementary Support Fund from Nottingham China Health Institute. Z. Lian acknowledges the financial support from the International Doctoral Innovation Centre, Ningbo Education Bureau, Ningbo Science and Technology Bureau, and the University of Nottingham. This work also received funding from UK Engineering and Physical Sciences Research Council under grant number: EP/J000582/1 and GR/R68078.

\section{References}

1 L. Bilińska, M. Gmurek and S. Ledakowicz, Comparison between industrial and simulated textile wastewater 
treatment by AOPs - Biodegradability, toxicity and cost assessment, Chem. Eng. J., 2016, 306, 550-559.

2 C. R. Holkar, A. J. Jadhav, D. V. Pinjari, N. M. Mahamuni and A. B. Pandit, A critical review on textile wastewater treatments: possible approaches, J. Environ. Manage., 2016, 182, 351-366.

3 K. Muda, A. Aris, M. R. Salim, Z. Ibrahim, A. Yahya, M. C. van Loosdrecht, A. Ahmad and M. Z. Nawahwi, Development of granular sludge for textile wastewater treatment, Water Res., 2010, 44, 4341-4350.

4 A. Spagni, S. Casu and S. Grilli, Decolourisation of textile wastewater in a submerged anaerobic membrane bioreactor, Bioresour. Technol., 2012, 117, 180-185.

5 U. Tezcan Un and E. Aytac, Electrocoagulation in a packed bed reactor-complete treatment of color and cod from real textile wastewater, J. Environ. Manage., 2013, 123, 113-119.

6 M. S. Nawaz and M. Ahsan, Comparison of physicochemical, advanced oxidation and biological techniques for the textile wastewater treatment, Alexandria Eng. J., 2014, 53, 717-722.

7 R. Zouzelka, Y. Kusumawati, M. Remzova, J. Rathousky and T. Pauporte, Photocatalytic activity of porous multiwalled carbon nanotube- $\mathrm{TiO}_{2}$ composite layers for pollutant degradation, J. Hazard. Mater., 2016, 317, 52-59.

8 R. Gupta and G. U. Kulkarni, Removal of organic compounds from water by using a gold nanoparticle-poly(dimethylsiloxane) nanocomposite foam, ChemSusChem, 2011, 4, 737743.

9 I. Park, K. Efimenko, J. Sjöblom and J. Genzer, Rapid Removal of Organics and Oil Spills from Waters Using Silicone Rubber "Sponges", J. Dispersion Sci. Technol., 2009, 30, 318-327.

10 A. Scott, R. Gupta and G. U. Kulkarni, A Simple Water-Based Synthesis of $\mathrm{Au}$ Nanoparticle/PDMS Composites for Water Purification and Targeted Drug Release, Macromol. Chem. Phys., 2010, 211, 1640-1647.

11 D. Zhu, S. Handschuh-Wang and X. Zhou, Recent progress in fabrication and application of polydimethylsiloxane sponges, J. Mater. Chem. A, 2017, 5, 16467-16497.

12 K.-S. Koh, J. Chin, J. Chia and C.-L. Chiang, Quantitative Studies on PDMS-PDMS Interface Bonding with Piranha Solution and its Swelling Effect, Micromachines, 2012, 3, 427-441.

13 D. N. H. Tran, S. Kabiri, T. R. Sim and D. Losic, Selective adsorption of oil-water mixtures using polydimethylsiloxane (PDMS)-graphene sponges, Environ. Sci.: Water Res. Technol., 2015, 1, 298-305.

14 S.-J. Choi, T.-H. Kwon, H. Im, D.-I. Moon, D. J. Baek, M.-L. Seol, J. P. Duarte and Y.-K. Choi, A Polydimethylsiloxane (PDMS) Sponge for the Selective Absorption of Oil from Water, ACS Appl. Mater. Interfaces, 2011, 3, 4552-4556.

15 X. Chen, J. A. Weibel and S. V. Garimella, Continuous OilWater Separation Using PolydimethylsiloxaneFunctionalized Melamine Sponge, Ind. Eng. Chem. Res., 2016, 55, 3596-3602.
16 A. Zhang, M. Chen, C. Du, H. Guo, H. Bai and L. Li, Poly(dimethylsiloxane) Oil Absorbent with a ThreeDimensionally Interconnected Porous Structure and Swellable Skeleton, ACS Appl. Mater. Interfaces, 2013, 5, 10201-10206.

17 A. Turco, E. Primiceri, M. Frigione, G. Maruccio and C. Malitesta, An innovative, fast and facile soft-template approach for the fabrication of porous PDMS for oil-water separation, J. Mater. Chem. A, 2017, 5, 23785-23793.

18 M. W. Toepke and D. J. Beebe, PDMS absorption of small molecules and consequences in microfluidic applications, Lab Chip, 2006, 6, 1484-1486.

19 B. J. van Meer, H. de Vries, K. S. A. Firth, J. van Weerd, L. G. J. Tertoolen, H. B. J. Karperien, P. Jonkheijm, C. Denning, I. J. AP and C. L. Mummery, Small molecule absorption by PDMS in the context of drug response bioassays, Biochem. Biophys. Res. Commun., 2017, 482, 323-328.

20 M. A. Iyer and D. T. Eddington, Storing and releasing rhodamine as a model hydrophobic compound in polydimethylsiloxane microfluidic devices, Lab Chip, 2019, 19, 574-579.

21 Y. Liu, L. Tian, X. Tan, X. Li and X. Chen, Synthesis, properties, and applications of black titanium dioxide nanomaterials, Sci. Bull., 2017, 62, 431-441.

22 K. Nakata and A. Fujishima, $\mathrm{TiO}_{2}$ photocatalysis: design and applications, J. Photochem. Photobiol., C, 2012, 13, 169-189.

23 V. Binas, D. Venieri, D. Kotzias and G. Kiriakidis, Modified $\mathrm{TiO}_{2}$ based photocatalysts for improved air and health quality, J. Materiomics, 2017, 3, 3-16.

24 S.-Y. Lee and S.-J. Park, $\mathrm{TiO}_{2}$ photocatalyst for water treatment applications, J. Ind. Eng. Chem., 2013, 19, 17611769.

25 M. A. Behnajady, H. Eskandarloo, N. Modirshahla and M. Shokri, Investigation of the effect of sol-gel synthesis variables on structural and photocatalytic properties of $\mathrm{TiO}_{2}$ nanoparticles, Desalination, 2011, 278, 10-17.

26 L. Zhang, H. H. Mohamed, R. Dillert and D. Bahnemann, Kinetics and mechanisms of charge transfer processes in photocatalytic systems: a review, J. Photochem. Photobiol., C, 2012, 13, 263-276.

27 J.-M. Herrmann, Fundamentals and misconceptions in photocatalysis, J. Photochem. Photobiol., A, 2010, 216, 85-93.

$28 \mathrm{M}$. Shiraishi and M. Ata, Work function of carbon nanotubes, Carbon, 2001, 39(12), 1913-1917.

29 B. Gao, C. Peng, G. Chen and G. Lipuma, Photo-electrocatalysis enhancement on carbon nanotubes/titanium dioxide $\left(\mathrm{CNTs} / \mathrm{TiO}_{2}\right)$ composite prepared by a novel surfactant wrapping sol-gel method, Appl. Catal., B, 2008, 85, 17-23.

30 K. Woan, G. Pyrgiotakis and W. Sigmund, Photocatalytic Carbon-Nanotube-TiO 2 Composites, Adv. Mater., 2009, 21, 2233-2239.

31 B. Gao, G. Z. Chen and G. Li Puma, Carbon nanotubes/ titanium dioxide $\left(\mathrm{CNTs} / \mathrm{TiO}_{2}\right)$ nanocomposites prepared by conventional and novel surfactant wrapping sol-gel methods exhibiting enhanced photocatalytic activity, Appl. Catal., B, 2009, 89, 503-509. 
32 P. Zhu, A. S. Nair, S. Yang and S. Ramakrishna, $\mathrm{TiO}_{2}-$ MWCNT rice grain-shaped nanocomposites-synthesis, characterization and photocatalysis, Mater. Res. Bull., 2011, 46, 588-595.

33 C. Liu, H. Chen, K. Dai, A. Xue, H. Chen and Q. Huang, Synthesis, characterization, and its photocatalytic activity of double-walled carbon nanotubes- $\mathrm{TiO}_{2}$ hybrid, Mater. Res. Bull., 2013, 48, 1499-1505.

34 S. B. A. Hamid, T. L. Tan, C. W. Lai and E. M. Samsudin, Multiwalled carbon nanotube/ $/ \mathrm{TiO}_{2}$ nanocomposite as a highly active photocatalyst for photodegradation of Reactive Black 5 dye, Chin. J. Catal., 2014, 35, 2014-2019.

35 L. Ling, C. Wang, M. Ni and C. Shang, Enhanced photocatalytic activity of $\mathrm{TiO}_{2} /$ single-walled carbon nanotube (SWCNT) composites under UV-A irradiation, Sep. Purif. Technol., 2016, 169, 273-278.

36 M. T. S. Tavares, A. S. F. Santos, I. M. G. Santos, M. R. S. Silva, M. R. D. Bomio, E. Longo, C. A. Paskocimas and F. V. Motta, $\mathrm{TiO}_{2} / \mathrm{PDMS}$ nanocomposites for use on self-cleaning surfaces, Surf. Coat. Technol., 2014, 239, 16-19.

37 R. Hickman, E. Walker and S. Chowdhury, $\mathrm{TiO}_{2}-\mathrm{PDMS}$ composite sponge for adsorption and solar mediated photodegradation of dye pollutants, J. Water Process. Eng., 2018, 24, 74-82.

38 Y. Lee, S. Lee, H. S. Kim, J. T. Moon, J. B. Joo and I. Choi, Multifunctional and recyclable $\mathrm{TiO}_{2}$ hybrid sponges for efficient sorption, detection, and photocatalytic decomposition of organic pollutants, J. Ind. Eng. Chem., 2019, 73, 328-335.

39 D. T. Vaimakis-Tsogkas, D. G. Bekas, T. Giannakopoulou, N. Todorova, A. S. Paipetis and N. M. Barkoula, Effect of $\mathrm{TiO}_{2}$ addition/coating on the performance of polydimethylsiloxane-based silicone elastomers for outdoor applications, Mater. Chem. Phys., 2019, 223, 366-373.

40 Y. Wang, Z. Huang, R. S. Gurney and D. Liu, Superhydrophobic and photocatalytic $\mathrm{PDMS} / \mathrm{TiO}_{2}$ coatings with environmental stability and multifunctionality, Colloids Surf., A, 2019, 561, 101-108.

41 S. S. Datta, A. Abbaspourrad, E. Amstad, J. Fan, S.-H. Kim, M. Romanowsky, H. C. Shum, B. Sun, A. S. Utada, M. Windbergs, S. Zhou and D. A. Weitz, 25th Anniversary Article: Double Emulsion Templated Solid Microcapsules: Mechanics And Controlled Release, Adv. Mater., 2014, 26, 2205-2218.

42 A. S. Utada, L. Y. Chu, A. Fernandez-Nieves, D. R. Link, C. Holtze and D. A. Weitz, Dripping, Jetting, Drops, and Wetting: The Magic of Microfluidics, MRS Bull., 2007, 32, 702-708.

43 A. R. Abate and D. A. Weitz, High-Order Multiple Emulsions Formed in Poly(dimethylsiloxane) Microfluidics, Small, 2009, 5, 2030-2032.

44 S. L. Anna and H. C. Mayer, Microscale tipstreaming in a microfluidic flow focusing device, Phys. Fluids, 2006, 18, 121512.

45 L. Cheng, B. Cai, Y. Zuo, L. Xiao, L. Rao, Z. He, Y. Yang, W. Liu, S. Guo and X.-Z. Zhao, Janus droplet parallel arrangements using a simple Y-channel flow-focusing microfluidic device, Chem. Phys. Lett., 2017, 673, 93-98.

46 Z. Liu, Y. Du and Y. Pang, Generation of Water-In-Oil-InWater $(\mathrm{W} / \mathrm{O} / \mathrm{W})$ Double Emulsions by Microfluidics, Chin. J. Anal. Chem., 2018, 46, 324-330.

47 T. Han, L. Zhang, H. Xu and J. Xuan, Factory-on-chip: modularised microfluidic reactors for continuous mass production of functional materials, Chem. Eng. J., 2017, 326, 765-773.

48 T. Li, L. Zhao, W. Liu, J. Xu and J. Wang, Simple and reusable off-the-shelf microfluidic devices for the versatile generation of droplets, Lab Chip, 2016, 16, 4718-4724.

49 Z. Lian, Y. Ren, J. He, G. Z. Chen and K. S. Koh, Microfluidic fabrication of porous polydimethylsiloxane microparticles for the treatment of toluene-contaminated water, Microfluid. Nanofluid., 2018, 22, 145.

50 J. Liu, L. Ye, S. Wooh, M. Kappl, W. Steffen and H. J. Butt, Optimizing Hydrophobicity and Photocatalytic Activity of PDMS-Coated Titanium Dioxide, ACS Appl. Mater. Interfaces, 2019, 11, 27422-27425.

51 Y. Lee, S. Lee, H. Kim, J. Moon, J. Joo and I. Choi, Multifunctional and Recyclable $\mathrm{TiO}_{2}$ Hybrid Sponges for Efficient Sorption, Detection, and Photocatalytic Decomposition of Organic Pollutants, J. Ind. Eng. Chem., 2019, 73, 328-335.

52 B. Bolvardi, J. Seyfi, I. Hejazi, M. Otadi, H. A. Khonakdar and S. M. Davachi, Towards an efficient and durable superhydrophobic mesh coated by $\mathrm{PDMS} / \mathrm{TiO}_{2}$ nanocomposites for oil/water separation, Appl. Surf. Sci., 2019, 492, 862-870.

$53 \mathrm{~T}$. Xu, Y. Cai and K. E. O'Shea, Adsorption and Photocatalyzed Oxidation of Methylated Arsenic Species in $\mathrm{TiO}_{2}$ Suspensions, Environ. Sci. Technol., 2007, 41, 54715477.

54 C. Zhao, M. Pelaez, D. D. Dionysiou, S. C. Pillai, J. A. Byrne and K. E. O'Shea, UV and visible light activated $\mathrm{TiO}_{2}$ photocatalysis of 6-hydroxymethyl uracil, a model compound for the potent cyanotoxin cylindrospermopsin, Catal. Today, 2014, 224, 70-76.

55 X. Hu, T. Mohamood, W. Ma, C. Chen and J. Zhao, Oxidative Decomposition of Rhodamine B Dye in the Presence of $\mathrm{VO}^{2+}$ and/or Pt(Iv) under Visible Light Irradiation: N-Deethylation, Chromophore Cleavage, and Mineralization, J. Phys. Chem. $B, 2006,110,26012-26018$.

56 X. Liu, Y. Liu, S. Lu, W. Guo and B. Xi, Performance and mechanism into $\mathrm{TiO}_{2}$ /Zeolite composites for sulfadiazine adsorption and photodegradation, Chem. Eng. J., 2018, 350, 131-147.

57 F. Peng, Y. Ni, Q. Zhou, J. Kou, C. Lu and Z. Xu, Fabrication of a flexible graphene- $\mathrm{TiO}_{2} / \mathrm{PDMS}$ photocatalytic film by combining air atmospheric pressure glow discharge treatment, Chem. Eng. Process., 2016, 101, 8-15.

58 M. Alshabanat, Applications of polystyrene/graphite composites in water purification as a semiconductor visible-light photocatalyst for organic pollutant degradation, Egypt. J. Aquat. Res., 2019, 45, 19-23. 
59 Z.-Y. Yang, G.-Y. Shen, Y.-P. He, X.-X. Liu and S.-J. Yang, Preparation of $\mathrm{TiO}_{2} / \mathrm{SiO}_{2}$ composite oxide and its photocatalytic degradation of rhodamine B, J. Porous Mater., 2016, 23, 589-599.
$60 \mathrm{H}$. M. Gad and A. A. El-Sayed, Activated carbon from agricultural by-products for the removal of Rhodamine-B from aqueous solution, J. Hazard. Mater., 2009, 168, 10701081. 